\title{
Heterogeneidades hidroestratigráficas no Sistema Aqüífero Guarani
}

\author{
Ana Paula Soares ${ }^{1}$ Paulo César Soares ${ }^{2}$ \& Michael Holz
}

\begin{abstract}
Resumo O principal aqüifero regional da América do Sul, Sistema aqǘfero Guarani, é composto principalmente das formações psamíticas Pirambóia e Botucatu (Brasil), Misiones (Paraguai e Argentina) e Taquarembó (Uruguai), com uma espessura máxima de $600 \mathrm{~m}$, de idades Triássica e Jurássica. Tais unidades sobrepõem discordantemente diferentes formações Paleozóicas e são cobertas por basaltos do Cretáceo. O aqǘfero não é um conjunto de arenitos homogêneos, mas composto da associação de fácies cujos elementos arquiteturais e geometria permitem subdividi-lo em unidades de fluxo. Estas unidades têm diferentes condutividades hidráulicas e, como conseqüência, um comportamento hidrodinâmico e hidroquímico diferencial. A análise estratigráfica, usando dados do campo e registros de poços exploratórios, permite construir um modelo de sistemas deposicionais e distribuição espacial das propriedades dos reservatórios. O aqüífero é dividido em três unidades de fluxo principais: duna (DU), interdunas (ID) e canais (CH); e secundariamente: crevasse (CR), lacustre e planície de inundação (FF). Cada uma tem características faciológicas e distribuição granular que permitem inferir a permeabilidade efetiva. A unidade DU da Formação Botucatu apresenta a condutividade hidráulica média numa ordem de magnitude maior que a unidade interduna da Formação Pirambóia, significando dez vezes o potencial da velocidade do fluxo da água. A unidade interduna úmida, intercalada com a unidade duna, da Formação Pirambóia pode ser considerada um aquitarde. Em afloramentos o topo da fácies interduna representa zona de descarga de água. As distribuições espaciais das unidades têm um efeito direto na qualidade e no fluxo da água dentro do aqǘ́fero regional.
\end{abstract}

Palavras-chave: heterogeneidades, hidroestratigrafia, Sistema Aqüífero Guarani.

\begin{abstract}
Hydrostratigraphics Heterogeneities on Guarani Aquifer System. The main regional aquifer of South America is the Guarani Aquifer System (SAG), it is made up mainly of the psamitic Pirambóia and Botucatu formations (Brazil), Misiones (Paraguay and Argentina) and Taquarembó (Uruguay), with a maximum thickness of $600 \mathrm{~m}$. The aquifer system lies unconformable over different Paleozoic formations and is covered by extensive basaltic flows of Early Cretaceous age. The aquifer is not a homogeneous blanket sandstone, but composed of facies association whose geometry and architectural elements allow to subdivide it in flows units. These units have different hydraulic conductivity and as consequence different hydrodynamic and hydrochemical behavior. Stratigraphic analysis using field and well data allows to construct a model of depositional systems and reservoirs properties distribution. The aquifer is divided in tree main flow unities: dune (DU), interdune (ID) and channel (CH); and secondary, two others: crevasse (CR), and lacustrine and flood plain (FF). Each one has facies characteristics, and the grain distribution allow inferring the effective porosity and permeability. Botucatu DU presents average hydraulic conductivity one order o magnitude grater than Pirambóia interdune, meaning ten times the potential of water flow velocity. The humid interdune blanket sands bellow Botucatu and interbeded in the Pirambóia dunes may be considered a strong aquitard. The space distributions of the unities have a direct effect in quality and flow of water inside the regional aquifer. The data and results lead to the recognition of five main regional stratigraphic domains around the Paraná basin.
\end{abstract}

Keywords: heterogeneity, hydrostratigraphy, Guarani Aquifer System.

INTRODUÇÃO Os arenitos da Formação Botucatu constituem os melhores reservatórios do Sistema Aqüífero Guarani (Araújo et al. 1995), na Bacia do Paraná. Predominavam extensos ergs associados a outros sub-ambientes desérticos, como wadis, indicados por fácies rudácea basal bem como depósitos lacustres, indicados por fácies pelítica laminada. A unidade estratigráfica sotoposta, Formação Pirambóia é composta de fácies arenosas, rudáceas e mais raramente pelíticas, eólicas, fluviais e lacustres.

As idades atribuídas a estas unidades, bem como suas relações de contato com as unidades acima e abaixo são conflitantes. Às unidades subjacentes mais jovens, formações Rio do Rasto e Santa Maria, atribuise idade permiana a eo-triássica (Rohn 1994); à unidade sobrejacente, Formação Serra Geral, atribui-se idade eo-cretácica (130-140 Ma; Turner et al. 1994).

O conhecimento detalhado das heterogeneidades dos aqüíferos é fundamental para a predição da circulação e armazenamento da água. A geometria externa e a compartimentação interna, dadas pelas estruturas sedimentares e litossomas, constituem a arquitetura do reservatório.

Os principais parâmetros que influenciam nos va-

1 - UFRGS, Programa de Pós-Graduação, Instituto de Geociências, Porto Alegre (RS), Brasil. E-mail: ana.paula.soares@petrobras.com.br

2 - PPGeol e UFPR, Curitiba (PR), Brasil. E-mail: p_soares@terra.com.br

3 - UFRGS, Instituto de Geociências, Porto Alegre (RS), Brasil. E-mail: Michael.holz@ufrgs.br 
lores de porosidade inicial em arenitos-reservatórios são associados à distribuição granulométrica: tamanho médio e seleção. Outros parâmetros como arredondamento, esfericidade e orientação dos grãos, podem modificar parcialmente o papel da seleção e do tamanho médio.

A composição mineralógica (Paim et al. 2003), empacotamento e mineralização diagenética contribuem significativamente na porosidade efetiva, tanto por compactação como por dissolução de minerais instáveis e reprecipitação de outros minerais durante sua história de soterramento e re-exposição.

Aqueles parâmetros primários são refletidos nos padrões de distribuição das fácies e dos sistemas deposicionais, o que permite o estabelecimento de um modelo hidroestratigráfico. Este, por sua vez, conduz uma delineação determinística da condutividade hidráulica, pré-requisito para acurada predição da história do fluxo e transporte por solução (Galloway \& Hobday 1996). Entretanto um elevado grau de inferência espacial está sempre presente, em parte estocástica e em parte controlada por fatores paleoambientais previsíveis.

A análise estratigráfica fornece um arcabouço de correlação nas quais as litofácies podem ser mapeadas e interpretadas, permitindo inferir os fatores paleoambientais; foca atenção na presença e distribuição das superfícies estratigráficas, de diferentes ordens de grandeza, nos estratos e suas relações, que resultam nas unidades do fluxo, com diferentes respostas hidráulicas, reduzindo-se assim a inferência estatística entre unidades de diferentes populações.

Por ser uma unidade de extensão regional (aproximadamente $1.200 .000 \mathrm{~km}^{2}$ ), o SAG é pouco conhecido enquanto aqǘ́fero, muitas vezes sendo considerado como um sistema homogêneo. É necessário conhecer suas descontinuidades geológicas e dinâmicas, para o gerenciamento da explotação dos recursos hídricos, direcionamento de investigações locais ou estabelecimento de estratégias de preservação mais eficientes.

As heterogeneidades litofaciológicas, diagenéticas, epigenéticas, além da estruturação regional por falhas, flexuras e intrusões, tornam o aqüífero complexo. Controlam a distribuição zonal de heterogeneidades associadas a restrições de fluxo, à mistura e ao tempo de residência da água (Rosa Filho et al., 1987). Expressivas descontinuidades hidráulicas e hidroquímicas no SAG são conhecidas, porém algumas incertezas exigem novas explicações para questões geológicas associadas, de tal forma que predições e inferências possam ser menos imprecisas. Quais são as unidades estratigráficas, como estão distribuídas e quais fatores controlam o comportamento como reservatório? Estas são as questões que se buscou responder com este trabalho.

Uma visão estratigráfica orientada ao estudo hidrogeológico pode contribuir para a caracterização do sistema aqǘfero num contexto global tanto do ponto de vista da hidráulica como da hidroquímica do SAG. Um novo enfoque para um velho problema é especialmente importante, considerando que grande parte da água potável acessível no atual estágio tecnológico encontra-se armazenada na forma de águas subterrâneas.
As ferramentas de análise da estratigrafia moderna, aplicadas ao estudo de aqǘf́eros, devem trazer os mesmos benefícios que a exploração/explotação de hidrocarbonetos experimentou. A sua aplicação na predição de propriedades do aqüífero é o principal propósito deste trabalho. Especificamente, dois objetivos são claros: (1) caracterização do arcabouço estratigráfico e estrutural, refletindo o potencial de conexões e o grau de compartimentação e isolamento de partes do sistema; (2) avaliação do significado destes compartimentos e conexões na dinâmica do sistema.

MÉTODOS O estudo da bibliografia sobre o SAG, revela uma história longa de avanços no conhecimento estratigráfico, da evolução diagenética, da estrutura e do fluxo, destacando-se os trabalhos de Araújo et al. (1995), Rosa Filho et al. 2003 e França et al. (2003), que abordaram o aqüífero na escala de bacia. Regionalmente diversos trabalhos contribuíram para compreensão do arcabouço regional do sistema aqüífero, desde o reconhecimento de diferentes fácies (Almeida 1954, Faccini 2000, Scherer 1998, Soares 1973), de direções de paleoventos (Bigarella \& Salamuni 1962, Assine 2004, Gianini et al. 2004), de diferentes unidades estratigráficas (Gamermam 1973, Bortoluzzi et al. 1987, Soares \& Landim 1973, Soares 1981, Scherer 1998), da organização estrutural (Soares 1974, 1992, Zalán 1986), da evolução diagenética (Caetano-Chang et al. 1991, França et al. 2003).

Dados originais foram trabalhados a partir das seguintes fontes (Fig. 1-B): (a) Perfis de poços exploratórios de petróleo em toda a bacia do Paraná (PETROBRAS e PAULIPETRO) e para carvão (CPRM), no Rio Grande do Sul: descrição litológica, perfis geofísicos (raio gama, resistividade e potencial espontâneo), $d i$ pmeter e de velocidade de perfuração; (Fig. 9-A); (b) Poços para água subterrânea (companhias de saneamento: CORSAN-RS, SANEPAR-PR, CETESB-SP, SANESUL-MS, Agência Nacional de Águas - ANA e Companhia de Pesquisa e Recursos Minerais - CPRM; (c) Banco de dados através do Sistema de Informação de Água Subterrânea - SIAGAS; CPRM, com grande volume de dados litológicos e hidrogeológicos; (d) Mapas geológicos locais, estaduais e regionais, em especial o Mapa Geológico do MERCOSUL, na escala 1:2.500.000 (DNPM/CPRM/DINAMIGE 1998): (e) Trabalhos de campo, distribuídos em diversas campanhas nas faixas de afloramentos do SAG incluído São Paulo, Mato Grosso do Sul, Paraná, Santa Catarina, Rio Grande do Sul e leste do Paraguai (Fig. 1-A). Os procedimentos de campo foram realizados conforme tabela 1, orientados pelas recomendações de Krause et al. 1987 (modificado por Paim et al. 2003 ).

Foram realizadas análises dos dados estruturais, descrição de fácies, relações de contato e caracterização da geometria externa dos corpos reservatórios que permitiram comparar as unidades. Verificaram-se as variações regionais e características de arquitetura das fácies, bem como a relação espacial e geométrica entre os diferentes sistemas deposicionais.

O trabalho com os perfis de poços incluiu a in- 


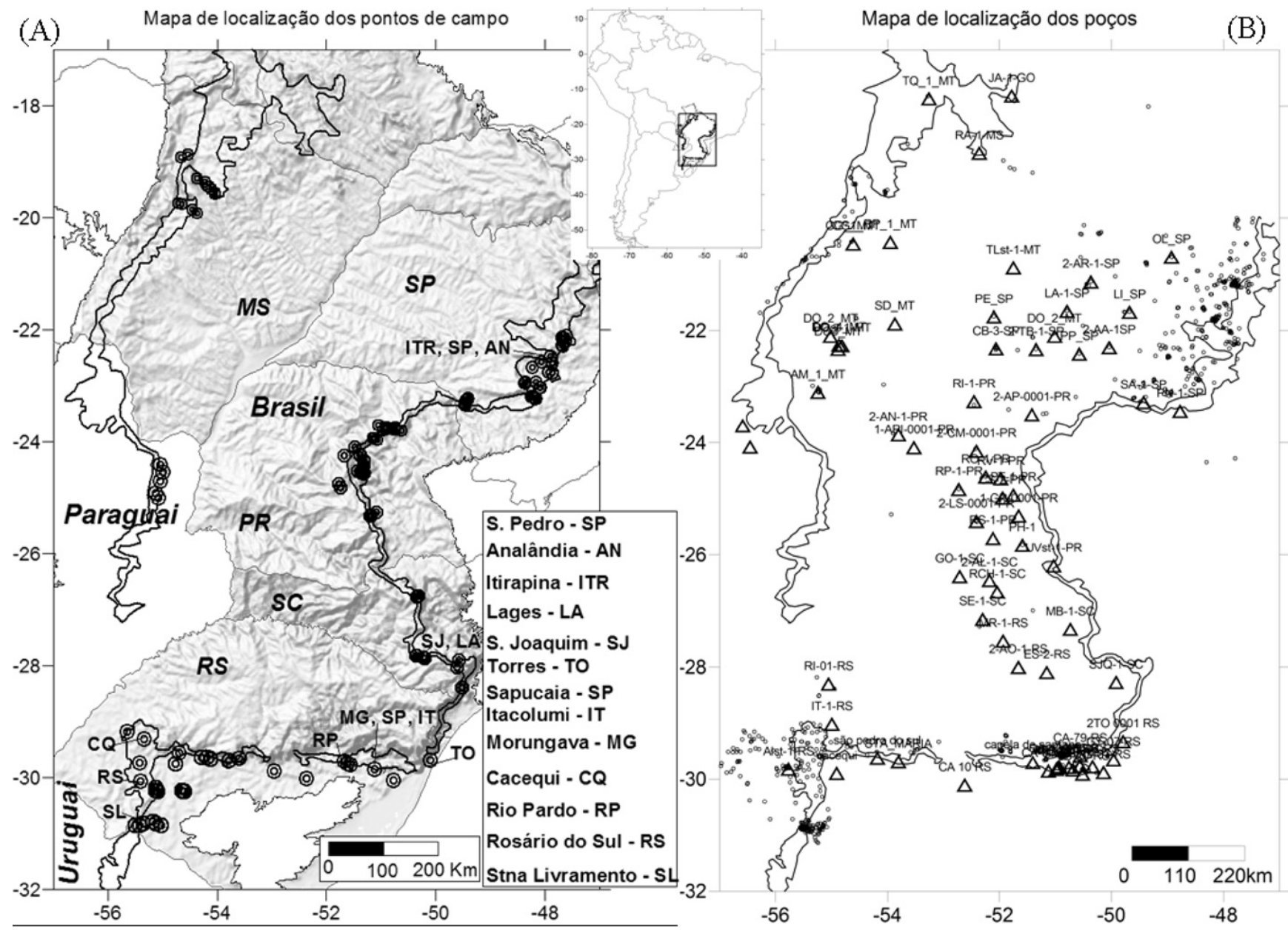

Figura 1 - Bacia do Paraná: (A) localização de pontos investigados no campo. (B) poços de petróleo (representado por triângulos no mapa) e água (do banco de dados do SIAGAS-CPRM,representados por pequenos círculos).

terpretação de fácies, correlação, caracterização de topo e base das unidades e a leitura de propriedades elétricas. Propriedades faciológicas e elétricas do reservatório e dos fluidos, descontinuidades estratigráficas e diagenéticas, direção de mergulho e corrente (dipmeter) foram trabalhadas e processadas de forma a obter informações sobre porosidade e propriedades das rochas e da água hospedada.

As informações resultantes das análises foram integradas de forma a obter-se a inter-relação das variáveis espaciais e possível relação com os atributos do sistema aqüífero, integrando informações de superfície e subsuperfície.

O reconhecimento de superfícies estratigráficas regionais, marcadoras de eventos climáticos, tectônicos, erosivos, deflacionais, de mudança de suprimento e direção de transporte; foram recursos usados sistematicamente. A identificação de litofácies, elementos arquiteturais e fácies elétricas; foram usados na definição e delimitação de unidades hidroestratigráficas e na interpretação da história deposicional.

Arcabouço Estratigráfico do SAG O SAG é constituido por diversas unidades hidroestratigráficas, caracterizadas em termos de condutividade hidráulica estimada ou medida, distinta das unidades vizinhas, podendo constituir tanto aqüíferos como aqüicludes ou aqüitardes. Podem ser identificadas nos diversos níveis de detalhe, equivalentes a formação, membro e camada. Por sua vez, as fácies, ou unidade litológica, pode constituir uma unidade de fluxo caracterizada por sua condutividade hidráulica homogênea. Outro componente hidroestratigráfico importante é a superfície de descontinuidade.

Os aqüíferos do SAG dispõem-se segundo três estilos de arranjo de fácies, no sentido de Weber e Van Geuns (1990). A unidade hidroestratigráfica Botucatu é do tipo tabular, contínua, Layer Cake, formada por amalgamação lateralmente contínua de corpos dunares. A Formação Pirambóia é caracterizada pelo estilo de variação lateral, amalgamada, irregular (quebra cabeça ou jigsaw puzzle), formada por combinação fácies eólica duna e interduna, fluviais e lacustres. Um terceiro tipo; o descontínuo, em cordões, ou labiríntico (labirinth) são típicos dos aqüíferos das unidades inferiores, Formação Santa Maria, no Rio Grande do Sul, formado pela presença de corpos formados em canais fluviais englobados por lamitos da planície aluvial.

Recentemente tem-se verificado a ocorrência 
Tabela 1 - Atributos reconhecidos nas distintas escalas de heterogeneidade de reservatório observados em campo (modificado de Paim et al. 2003 - adaptado de Krause et al., 1987).

\begin{tabular}{l|l|l|l}
\hline \multirow{2}{*}{} & ELEMENTOS GEOLÓGICOS & MACROESCALA & MEGAESCALA \\
\cline { 2 - 4 } & Mineralogia & $\begin{array}{l}\text { Variações composicionais => associações de } \\
\text { fácies }\end{array}$ & Variações composicionais regionais \\
\cline { 2 - 4 } & Granulometria e seleção granulométrica & $\begin{array}{l}\text { Distribuição através da Unidade } \\
\text { Hidroestratigráfica => Associação de litofácies }\end{array}$ & $\begin{array}{l}\text { Tendências regionais => sistemas/ } \\
\text { ambientes deposicionais }\end{array}$ \\
\cline { 2 - 5 } & $\begin{array}{l}\text { Distribuição e controle da porosidade em } \\
\text { relação às associações de litofácies }\end{array}$ & Tendências regionais \\
\cline { 2 - 5 } & Rede de poros & $\begin{array}{l}\text { Estratificação e geometria das litofácies, } \\
\text { definindo sentido preferencial de fluxo }\end{array}$ & $\begin{array}{l}\text { Arquitetura estratigráfica definindo a } \\
\text { distribuição regional de litofácies }\end{array}$ \\
\cline { 2 - 5 } & Continuidade litológica & $\begin{array}{l}\text { Distribuição e orientações } \\
\text { Tendências regionais definindo blocos }\end{array}$ \\
\cline { 2 - 5 } & Fraturas e falhas & $\begin{array}{l}\text { Definições de frentes diagenéticas de } \\
\text { dissolução ou cimentação }\end{array}$ & $\begin{array}{l}\text { Tendências regionais de distribuição de } \\
\text { condições permoporosas }\end{array}$ \\
\hline
\end{tabular}

de variações regionais significativas, tanto faciológicas como nas relações de contato. Em virtude disto, as unidades componentes do SAG são descritas por regiões, afim de ressaltar as diferenças e caracterizar a compartimentação estratigráfica influente no sistema hidrogeológico. Cinco compartimentações são consideradas: Noroeste e Oeste (SAGNW-W), Nordeste e Centro Leste (SAGNE-E), Sudeste (SAGSE), Sul (SAGSUL) e Interior (SAGIN)

SAGNW-W A Formação Pirambóia, possui aproximadamente $250 \mathrm{~m}$ de espessura. São fácies areníticas de cor creme e castanho claro, granulometria variando entre grossa e fina, com matriz lamítica em torno de $10 \%$. Predominam arenitos médios, composto de quartzo, feldspato $(<10 \%)$ e minerais opacos (traços), com grãos foscos e subarredondados; cimentação e concreções carbonáticas são comuns em zonas descontínuas (Fig. 2-E,-F).

Estratificações plano-paralelas e cruzadas de baixo ângulo caracterizam os elementos de interduna úmida, intercaladas com estratificações cruzadas tabulares de duna. Nota-se um aumento da espessura dos sets em direção ao topo, variando de 0,5 a $5 \mathrm{~m}$. A direção de mergulho predominante é para nordeste e sudoeste.

Em subsuperfície, próximo ao depocentro da bacia, acrescentam-se arenitos de granulometria grossa e mal selecionados, com intercalações pelíticas. São depósitos de canal e crevasse do sistema fluvial. Paleocorrentes, identificadas em perfis dipmeter, predominam para sul. As fácies de interduna são dominantemente lençóis de areia, com raros depósitos subaquosos, o que permite interpretar como região de deserto seco, sem lençol freático aflorante, o que a torna mais semelhante à Formação Botucatu.

A Formação Botucatu é composta por arenito castanho e creme avermelhado, com espessura muito variável, desde 0 a $70 \mathrm{~m}$. Possui granulometria grossa e fina, bimodal, grãos arredondados, selecionados, esféri$\cos$ e foscos, com matriz quase ausente. Compostos por quartzo e subordinadamente por feldspato e opacos.

Os grãos são cobertos por película de óxido de ferro e muitas vezes ocorrem cimentação carbonática posterior ao ferro, causando completo fechamento dos poros. Localmente, o arenito está muito fraturado e silicificado na faixa de afloramento.

Apresenta estratificação cruzada tabular e tangencial na base (Fig. 2-A e B), com sets de até 8m que compõem fácies de duna e interduna seca, e estratos rítmicos, bem delineados, com direções de paleocorrente para NE.

O contato das formações Pirambóia e Botucatu é identificado por uma superfície que delimita a diferenciação de cor e granulometria dos arenitos (Fig. 2-C). Fendas na superfície arenosa do topo da Formação Pirambóia (Fig. 2-D), recobertas pelos arenitos eólicos da Fm. Botucatu, revelam longa exposição das areias desérticas. Estas fendas são interpretadas como sendo formadas pela contração termal noturna em desertos frios, típicos de médias latitudes, formando aberturas que vão sendo preenchidas por areia ("fentes en coin", Campy e Macaire, 1989) e indicam um evento de mudança climática antecedendo a cobertura por areias eólicas de ambiente super-árido da Formação Botucatu, e uma supersuperfície marcadora de linha de tempo, que justapõe fácies heterogêneas.

O contato com a unidade basáltica da Formação Serra Geral ora corta a estratificação, em superfície de deflação, e ora acompanha a superfície deposicional, chegando a preservar feições geométricas da duna ativa (Holz et al. 2007). Na região, a espessura do basalto varia de 0 a $350 \mathrm{~m}$.

A correlação entre os poços da região (Fig. 3) mostra claramente que de norte para sul, as formações Aquidauana, Passa Dois (Corumbataí e Teresina) e Rio do Rasto (Serrinha e Morro Pelado, seqüência permocarbonífera da Bacia do Paraná) fazem contato com a formação Pirambóia através de uma discordância angular. Os contatos basais apresentam quebras notáveis nos perfis de resistividade. Em campo, algumas características como brechas, lateritas, silexitos e paleossolos indicam exposição e longo tempo envolvido na superfície de discordância que precedeu a deposição dos depósi- 


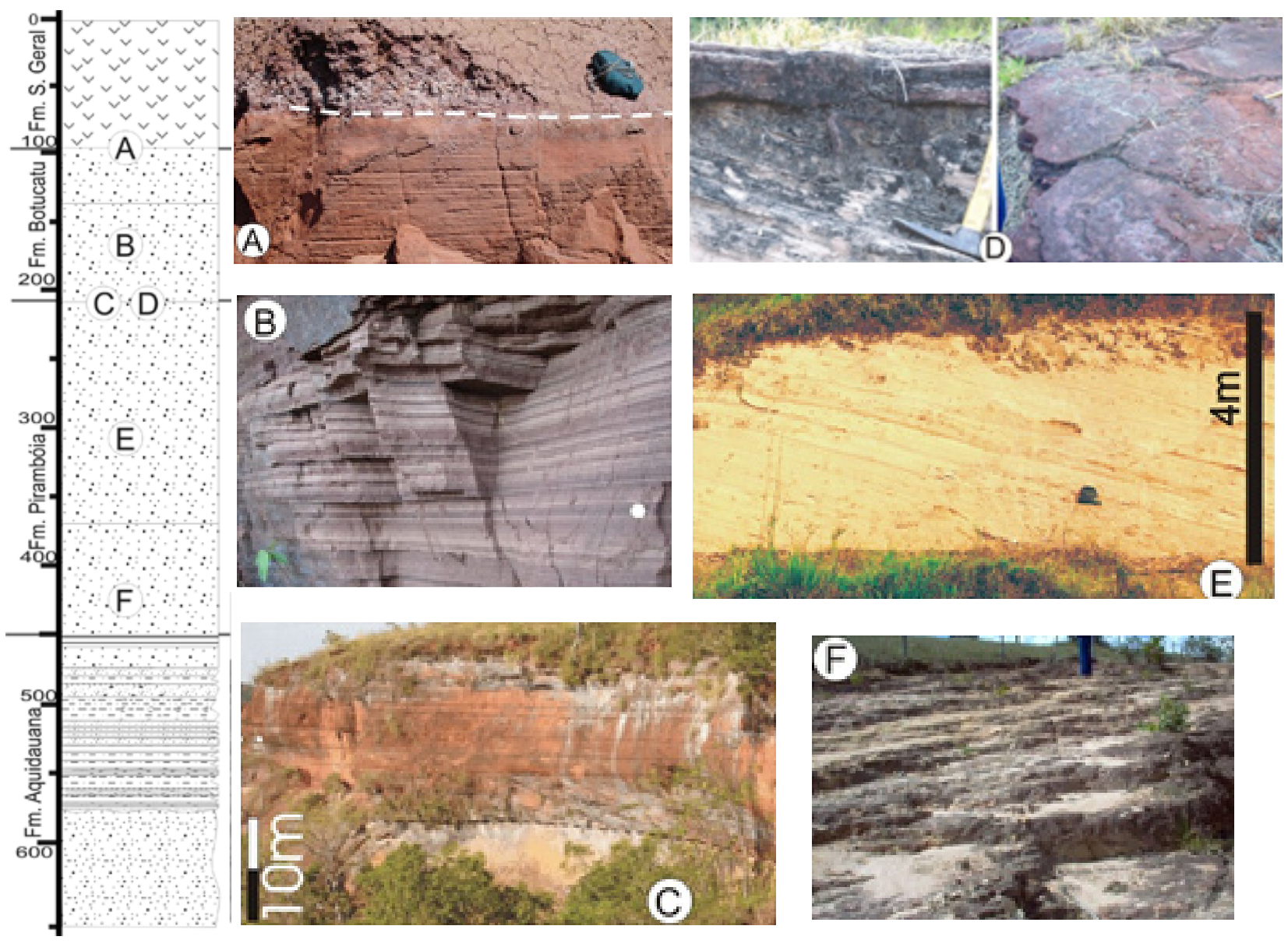

Figura 2 - (A) contato entre basalto da Formação Serra Geral e arenito da Formação Botucatu; (B) Arenito com estratificação cruzada da Formação Botucatu; (C) contato entre Formações Pirambóia e Botucatu, evidenciado por fraturas poligonais (em perfil e planta). (D) Contato entre as Formações Pirambóia e Botucatu; (E) arenito com estratificação de baixo ângulo - base Formação Pirambóia; (F) arenito fino (Fm. Pirambóia) com estratificação cruzada, notar concreções de carbonato.

tos desérticos.

Ressaltam-se ainda características diferenciais entre os arenitos das formações Botucatu e Pirambóia: (1) valores de raio gama menores, resultado do menor teor de feldspato e de argilas; (2) valores resistividade maior, revelando o caráter mais limpo dos arenitos e águas menos salinizadas; (3) valores maiores de SP, indicando a maior porosidade saturada em água.

SAGNE-E Nesta porção as unidades confinantes sotopostas são da Formação Teresina ou Corumbataí (Fig. 4-I) e Formação Rio do Rasto, este mais a sul. No extremo nordeste o SAG sobrepõe-se em discordância diretamente sobre a Formação Aquidauana, estendendo-se até alcançar o embasamento Cristalino, com omissão da Formação Pirambóia (Soares \& Landim 1973).

O limite basal do SAG é formado por um contato discordante, evidenciado pela presença de brechas de silexito, representando um hiato no qual ocorreu a silicificação dos calcários coquinóides da Formação Teresina. Estão presentes paleossolos com marcas de raiz e leve angularidade nos acamamentos (Fig. 4-H) e penetração de areia eólica em juntas dos siltitos. $\mathrm{Na}$ faixa aflorante, o contato é bem marcado pela quebra de relevo. Em subsuperfície a quebra e mudança de padrões nos perfis elétricos são evidentes.

Sobre o paleorelevo esculpido na discordância, instalou-se o sistema eólico da Formação Pirambóia, composto por fácies genéticas de dunas e interdunas úmidas, lateralmente associados a espessos pacotes de depósitos fluviais.

$\mathrm{Na}$ parte inferior predominam arenitos de cor creme, bimodais, variando entre muito fino a médio, de regular seleção, grãos subarredondados, com matriz, em torno de $10 \%$. Arenitos com estratificação cruzada tangencial (sets de até $3 \mathrm{~m}$ ), truncados por superfícies de deflação planas ( $2^{\mathrm{a}}$ ordem) (Fig. 4-F). Os depósitos de lençóis de areia possuem estruturas de adesão e bioturbações, pequenos canais e pelitos lacustres, portadores de ostracodes e conchostráceos (Fácies Santana, de Almeida,1954), com até $20 \mathrm{~cm}$ de espessura. São acumulações eólicas em dunas com paleocorrente multimodal, preferencialmente para norte e sudoeste;

Localmente a Formação Pirambóia apresenta 


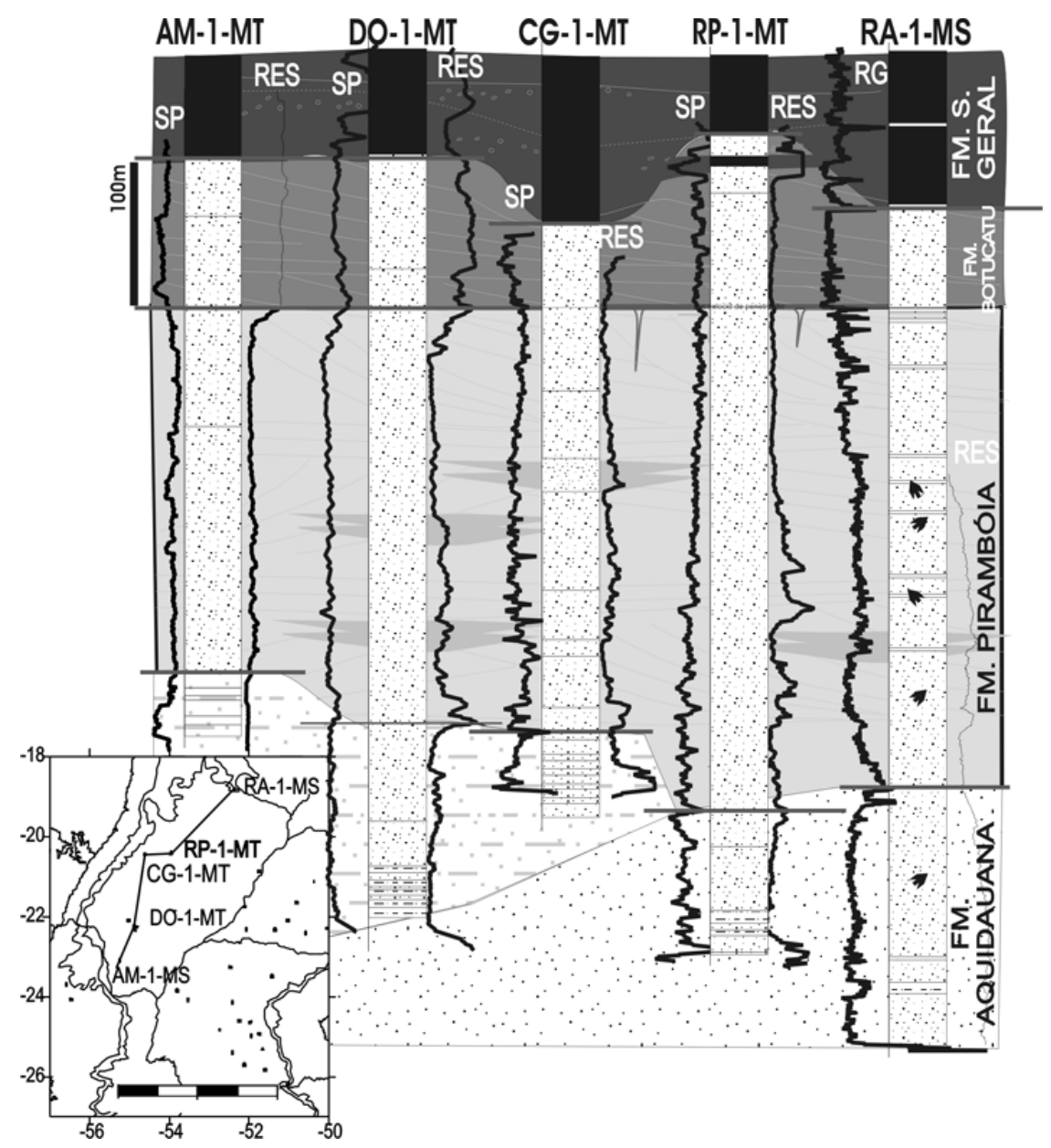

Figura 3 - Seção estratigráfica de poços a noroeste do SAG, estado do Mato Grosso do Sul, nivelada na base da Formação Botucatu. Observar a discordância pré-Pirambóia, cortando diferentes unidades e variação geomórfica de espessura do Botucatu (Perfis: SP - potencial espontâneo, $R E S$ - resistividade, $R G$-raios gama).

depósitos fluviais de deserto (oueds ou wadis), exibindo principalmente fácies de barras de canais rasos, resultante de rede de canais de sistema entrelaçado. São barras com geometria de corpos em lençol, multiepisódicos, representadas por estratos espessos de arenitos sub-arcósios, de granulometria grossa e conglomeráticos, mal selecionados e subangulosos, com repetidos sets de estratificação de pequeno porte (Fig. 4-E).

Exemplos típicos destas fácies ocorrem em São Pedro, Analândia e Itirapina (SP, AN e ITR - localização Fig. 1), onde chega a alcançar uma centena de metros de espessura. Também está presente no sul de São Paulo, estendendo-se até a parte central do Paraná (rodovia do Café) e oeste de Santa Catarina (RCH-1-SC).

Paleocorrentes nos canais estão preferencialmente orientadas para sudoeste e oeste, conforme já verificado por Assine et al. (2004). Depósitos de planície aluvial e crevasse, representados por pelitos intercalados com arenitos médios quartzosos e maciços são pouco freqüentes (Fig. 4-G).

A distribuição das espessuras da Formação
Pirambóia é variável, desde 80 a 300m de espessura aflorante. Tende a diminuir a espessura para nordeste onde desaparece entre as formações Aquidauana e o Botucatu, e para sul em direção à charneira do Arco de Ponta Grossa, no estado do Paraná, com apenas $20 \mathrm{~m}$ de espessura (Fig. 9-A). De uma forma geral há uma tendência a espessar para oeste, especialmente em direção a calha da bacia. A variação de espessura é relativamente grande, evidenciando uma atividade sin-tectônica na parte inferior (Artur \& Soares 2002).

O contato com a Formação Botucatu varia conforme o local. Por vezes assenta-se sobre a Formação Pirambóia com superfícies erosivas da fácies torrencial conglomerática (Fig. 4-B). Isso ocorre quando a passagem é entre elementos fluviais de ambas as unidades. Outras vezes a passagem ocorre entre elementos de sistema eólico, mudando cor e granulometria, teor de matriz (Fig. 4-D), tamanho dos sets e mergulho da estratificação cruzada.

Em diversos locais a base da Formação Botucatu é composta por arenitos conglomeráticos com grânu- 


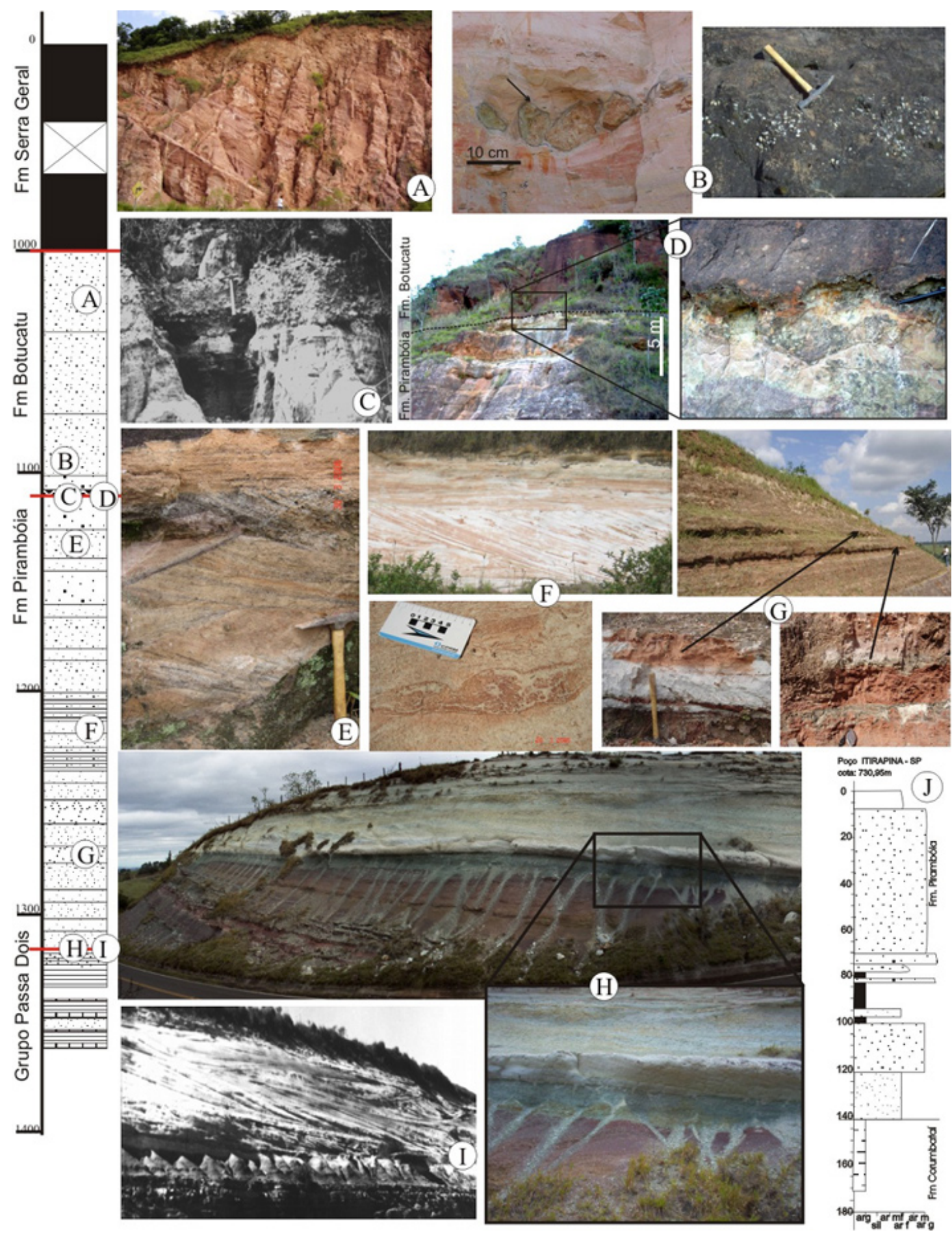

Figura 4 - Coluna estratigráfica regional composta para a parte central do estado de São Paulo. (I) Arenitos dunares da formação Pirambóia assentam-se em discordância, com paleossolo litólico e brecha silexítica, sobre a Formação Corumbatai em São Paulo (rodovia Castelo Branco); ou (H) sobre paleossolo esverdeado, com cunhas de areia, no Formação Rio do Rasto (Morro Pelado), no Paraná (Sapopema), em superfície discordante com leve angularidade. Fácies de duna, com estratos cruzados $(F)$ sotopostos a fácies de interduna, com acamamento subhorizontal de areias maciças e bioturbação; leitos peliticos $(G)$ na interduna (Serra de Santana, São Paulo) portadores de conchostráceos e ostracodes. Arenitos grossos fluviais (E), conglomeráticos (C) da Fm. Pirambóia, superposto por banco conglomerático da base da Fm. Botucatu (D, Serra de Franca), contatos abruptos entre arenitos eólicos de ambas formações, marcados pela presença de clastos de argila e bolsões de seixos de quartzo (B) e arenitos eólicos Botucatu(A). A seção foi composta com base em seções de Soares, 1975; informações da Serra de Santana, e poço de Itirapina, S.P (perfil à direita) foram usadas para posicionar os arenitos fluviais da foto $E$. 
los e seixos de quartzo sub-arredondados (Fig. 4-C) de até $8 \mathrm{~m}$ de espessura. Por vezes, apresentam abundantes clastos argilosos decimétricos (Fig. 4-B).

Os arenitos eólicos da Formação Botucatu são avermelhados, bimodais, com granulometria grossa e fina, bem selecionados, foscos e arredondados. Possui estratificação de grande porte, com sets de até $20 \mathrm{~m}$ (Fig. 4-A), resultado da migração de grandes dunas. Eventualmente intercalados com interdunas secas, truncadas por superfícies inclinadas. As paleocorrentes são polimodais, sendo preferencialmente para norte-noroeste e sudoeste, provavelmente indicando domínios eólicos de inverno e de verão. A espessura varia localmente entre 80 e 120m (Fig. 9-B), revelando uma causa morfológica da topografia dunar e a intercalação precoce dos derrames basálticos da Formação Serra Geral, que recobrem os arenitos dunares em diferentes níveis, ora em superfícies erosivas, ora deposicionais.
O conjunto de derrames chega a ter mais de $1600 \mathrm{~m}$ de espessura na parte central (PE-1-SP). Localmente em altos estruturais, os basaltos foram inteiramente removidos antes da deposição do Grupo Bauru (Soares 1974).

O SAGSE No Sudeste da Bacia a Formação Rio do Rasto limita o SAG na base com grande espessura nesta região. Predominam tonalidades arroxeadas, esverdeadas e avermelhadas, revelando uma condição supergênica progressivamente oxidante. A Formação Pirambóia recobre esta unidade em discordância, evidenciada por brechas e paleossolos (Fig. 5-C).

Na região, a Formação Pirambóia é formada por arenitos esbranquiçados, predominando granulometria muito fina e média, friáveis, com matriz lamítica e cimentação parcial por argila e calcedônia. Esta unidade tem espessura média de $80 \mathrm{~m}$, variando de 30 a

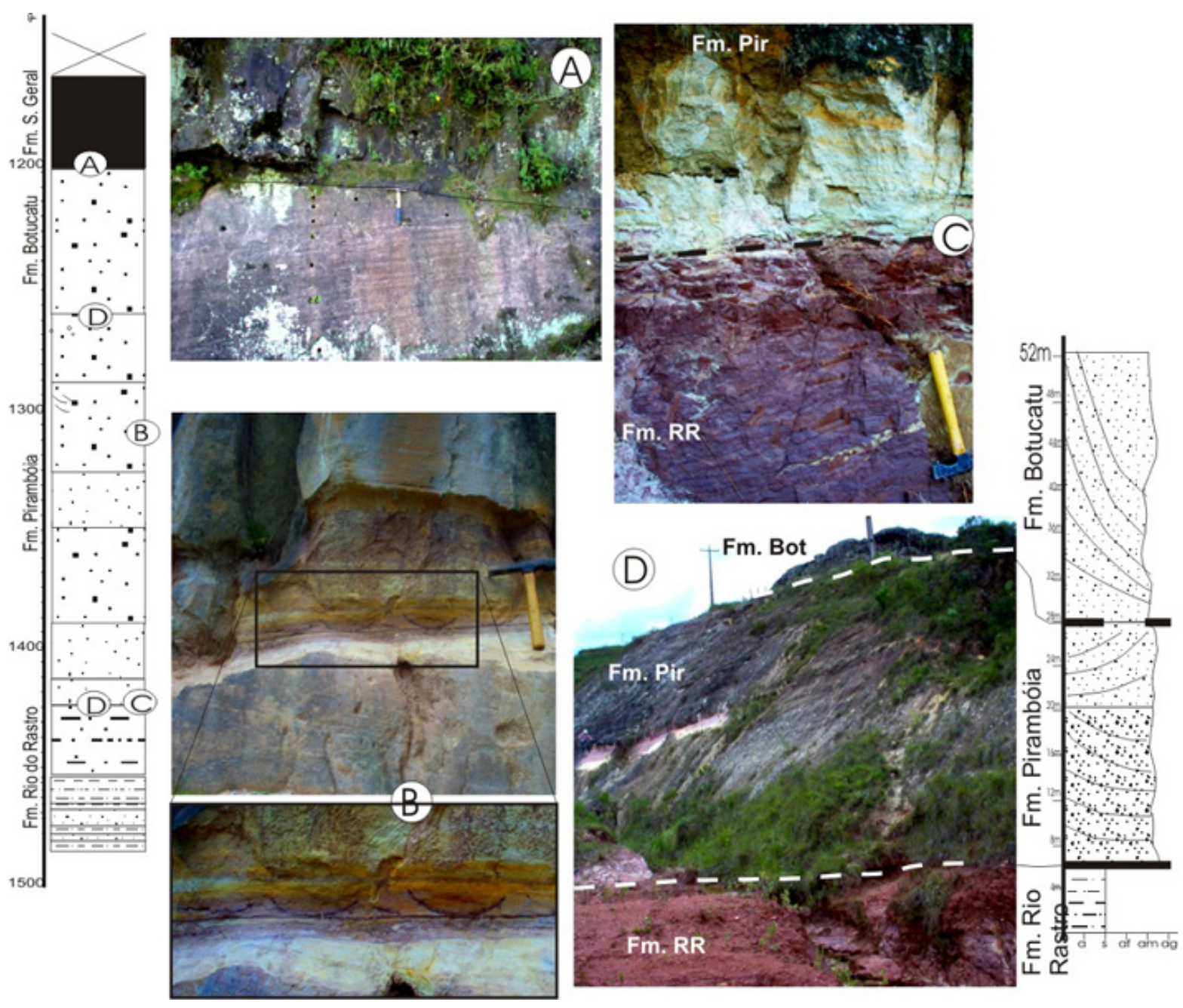

Figura 5 - Relações entre as formações Serra Geral, Botucatu, Pirambóia e Rio do Rasto no Estado de Santa Catarina. À esquerda perfil litológico na Serra do Rio do Rasto (A) Contato Formação Serra Geral, recobrindo uma superficie de deflação da Formação Botucatu - Serra do Rio do Rasto. (B) Fácies de interduna da Formação Pirambóia, com destaque para lâminas encurvadas em pelitos, formadas por ressecamento e contração (idem); (C) contato entre as formações Pirambóia e Rio do Rasto com registro de paleosolo litólico. (D) Corte com destaque para espessura localmente reduzida da formação Pirambóia, conforme o perfil litológico (Lages, rodovia para São Joaquim, SC). 
$200 \mathrm{~m}$, com espessamento para oeste, próximo à calha da bacia (Fig. 9-A).

Estratificações cruzadas de pequeno porte e baixo ângulo indicam paleoventos predominantes para norte e sudeste. Aumentam o tamanho dos sets e ângulos de mergulho em direção ao topo. Intercalam-se arenitos com estratificação plano-paralela, estruturas de corrugação, gretas de contração (Fig. 5-B) e bioturbações. Estas feições revelam a presença de água na fácies de interduna.

$\mathrm{Na}$ parte oeste apresenta características de depósitos fluviais, com intercalações de pelitos e arenitos, observadas em poços (GO-1-PR). A passagem para a Formação Botucatu é gradacional, ressaltadas no relevo (Fig. 5-D), com mudança de cor para castanho e rosado, e de granulometria fina para média, bem selecionada, com menor teor de matriz.

Assim como noutras regiões, a Formação Botucatu é exposta numa faixa estreita e contínua, com espessura média de $50 \mathrm{~m}$. Constituída por arenitos rosados, grãos bem selecionados, foscos e quartzosos, com granulometria fina e média, bimodais, com pouca matriz; grãos soltos e mais raramente silicificados. Os sets de estratificações cruzadas tangenciais chegam a $15 \mathrm{~m}$ de altura.

$O S A G S U L$ A região apresenta a maior complexidade faciológica e estratigráfica. São incluídos os depósitos equivalentes às formações Pirambóia, Santa Maria e Guará, com extensão à formação Taquarembó. Todas são recobertas pela Formação Botucatu, e sobrepostas às formações Rio do Rasto e Sanga do Cabral (Permiano ou Permo-Triássico) (Fig. 7).

No oeste e centro do Rio Grande do Sul, abaixo dos reservatórios do SAGSUL e sobre fácies de planícies aluviais da Formação Rio do Rasto, ocorre espesso pacote de arenitos eólicos de ambiente desértico $(80 \mathrm{~m})$. Acima dos arenitos eólicos, foi identificada uma seção fossilífera de idade acima, mas próxima ao limite Permo-Triássico (Eo-Scitiano, Lavina et al. 1993), razão que levou este autor a considerar a formação Pirambóia como Permiana. Posteriormente, Scherer (1998) mapeou uma unidade fluvio-eólica entre as formações Botucatu e Rosário do Sul ou Sanga do Cabral, em posição equivalente a Formação Santa Maria, porém com fósseis de idade Jurássica, que designou Formação Guará (Scherer \& Lavina, 2005).

Assim, em discordância inter-regional, sobre as formações Sanga do Cabral e Rio do Rasto, o SAGSUL, composto de depósitos eólicos e fluviais da seqüência mesozóica, apresenta uma divisão estratigráficoestrutural organizada em três blocos diferentes: oeste, central e leste. Nesta seqüência, três tratos de sistemas deposicionais podem ser identificados: um trato flúviolacustre; um trato flúvio-eólico com interduna úmida e um trato de dunas com interduna seca.

Bloco central (C) Estende-se para noroeste até a parte axial da bacia, o primeiro trato, em discordância sobre o Permiano (e localmente Eo-Scitiano), apresenta espessuras de até $160 \mathrm{~m}$ com diversidade de fácies e fósseis. É composto por três unidades, verticalmente empilhadas, com relações de interdigitação: unidades psamítica (Mb. Passo das Tropas) e pelítica (Mb. Alemoa) da Formação Santa Maria e unidade psamítica da Formação Caturrita.

O Membro Passo das Tropas, com aproximadamente $40 \mathrm{~m}$ de espessura, é formado por arenitos cinzentos conglomeráticos, feldspáticos, micáceos, com estratificação cruzada tangencial de pequeno porte. Constitui o principal sistema aqüífero na região central. Apresenta fósseis vegetais da flora Dicroidium de idade Meso-Triássica. Suas fácies são registros de rios entrelaçados, possivelmente como leques aluviais. Assenta-se discordantemente sobre a Formação Sanga do Cabral. O contato basal é marcado por uma superfície erosional, com hiato deposicional paleontológico definido entre o Triássico inferior e médio (Faccini 1989; Schultz 1995). Representa um episódio de soerguimento regional e erosão em clima quente e seco, com espessa zona de fraca laterização.

O contato superior é representado por interdigitação com pelitos vermelhos, lacustres e de planície de inundação, com intercalações de caliche, do Membro Alemoa, com espessura variando entre $20-50 \mathrm{~m}$. Intercalados e sobrepostos a este pacote pelítico vermelho ocorrem corpos lenticulares de arenitos de granulometria grossa a fina, frequentemente com clastos de argila, com estratificação cruzada, designados Formação Caturrita, com até 60m de espessura (Bortoluzzi et al., 1987). Registra um sistema fluvial anastomosado com canais múltiplos com paleocorrentes para nordeste (Soares et al. 2007). Fósseis indicam idade Neo-Triássica, podendo estender-se ao início do Jurássico (Schultz 1995).

A Formação Botucatu recobre descontinuamente este trato de sistemas, com espessura pequena, e registrando a ausência de uma seção, a do trato de sistemas eólico-fluvial.

Bloco oeste $(W) \quad$ Neste bloco está ausente o primeiro trato de sistema. O segundo trato foi designado Formação Guará (Scherer \& Lavina, 2005), que se estende para o Uruguai, onde é conhecido com a designação de Taquarembó (parte inferior). São arenitos de cores claras, muito semelhantes ao descritos da Formação Pirambóia, com até $160 \mathrm{~m}$ de espessura, incluindo depósitos fluviais e eólicos. Encontra-se em discordância sobre a Formação Sanga do Cabral (Neo-Permiano a Eo-Scitiano) ou Rosário do Sul (sensu stricto), com contraste de cores, vermelho e castanho avermelhado escuro, mas também portadoras de depósitos eólicos e fluviais.

A formação Guará, na parte sul da faixa, como em Santana do Livramento (SL, localização Fig. 1), compõe-se predominantemente de arenitos creme claro, muito-finos, finos e médios, com matriz, grãos subarredondados, boa a moderada seleção; organizam-se fácies de dunas, com estratificação cruzada, interacamados com fácies de interdunas úmidas, estratificação subhorizontal, ondulada, maciço e lenticular. Lateralmente, para norte, em direção a Santiago, predominam asso- 
ciações de fácies com arenitos creme claro, levemente esverdeados, de granulometria fina a grossa, regular seleção e arredondamento. Possui estratificação cruzada tangencial de pequeno a médio porte, climbing ripples e laminação plano-paralela. Registram o estabelecimento de um sistema fluvial entrelaçado com canais bem desenvolvidos, com fluxo para sudoeste, entremeados de campos de dunas com ventos vindos do Sudoeste. Paleossolos esverdeados, cunhas de arenito e interduna úmida, indicam mudança para condições de deserto de clima temperado a frio e freático sub aflorante.

A formação Botucatu, com fácies dunares de areias finas a média, cores rosadas, espessura muito variável (0 a 200m) recobre em delgado lençol a Formação Guará. Representando uma fase de intenso retrabalhamento das areias em deserto de clima quente e seco, com nível freático profundo, com ventos soprando de sudoeste.

Bloco leste (E) A Formação Sanga do Cabral e o primeiro ciclo Meso-Neo-Triássico estão ausentes. Fácies de canais fluviais e eólicas sobrepõem-se em discordância erosiva com angularidade baixa sobre a Formação Rio do Rasto. Estes depósitos fluviais são basais na seção, compostos por arenitos feldspáticos, castanho claro, de granulometria grossa, com clastos de argila. São recobertos por depósitos eólicos, médios, castanho claro com pintas brancas de calcedônia e argilas, e manchas ferruginosas. Têm até $140 \mathrm{~m}$ de espessura, predominantemente formados por fácies de dunas interacamados com fácies de interdunas úmidas ou secas.
Apresentam-se de forma contínua, para leste em rodovias e cavas de arenito; estão sotopostas à Formação Botucatu. Estendem-se para a parte norte, em subsuperfície, no compartimento sudeste da bacia (Torres-RS, São Joaquim-SC e Lages-SC, localização Fig. 1), mostrando a continuidade física com a Formação Pirambóia, o que é facilmente verificado em perfis de poços. Embora com arquitetura de fácies diferente, esta unidade se correlaciona com a Formação Guará, sendo considerada como pertencente ao SAG (Soares et al. 2007). As direções medidas mostram sistematicamente ventos provenientes de leste. Na transição para a unidade superior, (Formação Botucatu), ocorrem intercalações de fácies dunares semelhantes, porém com mudança de direção de paleocorrente para Nordeste.

A Formação Botucatu está presente nos três blocos, com espessuras predominantemente pequenas, mas eventualmente atingem até $80 \mathrm{~m}$. São arenitos finos, bimodais, maturos, estratificação de porte muito grande, alto ângulo, cores castanho-claras (Fig. 6). O contato, com a Formação Guará a oeste, é abrupto, com variação de cor, superfície deflacional, com cunhas arenosas poligonais ("fentes em coin"), indicadoras de longa exposição. Superfícies erosivas, conglomerados basais com concentração de seixos por deflação, ocorrem no bloco central sobre a Formação Caturrita. No leste, com a Formação Pirambóia, é transicional, revelando apenas uma progressão, por intercalação, para depósitos em grandes ergs, com dunas elevadas e alto ângulo de estabilidade.

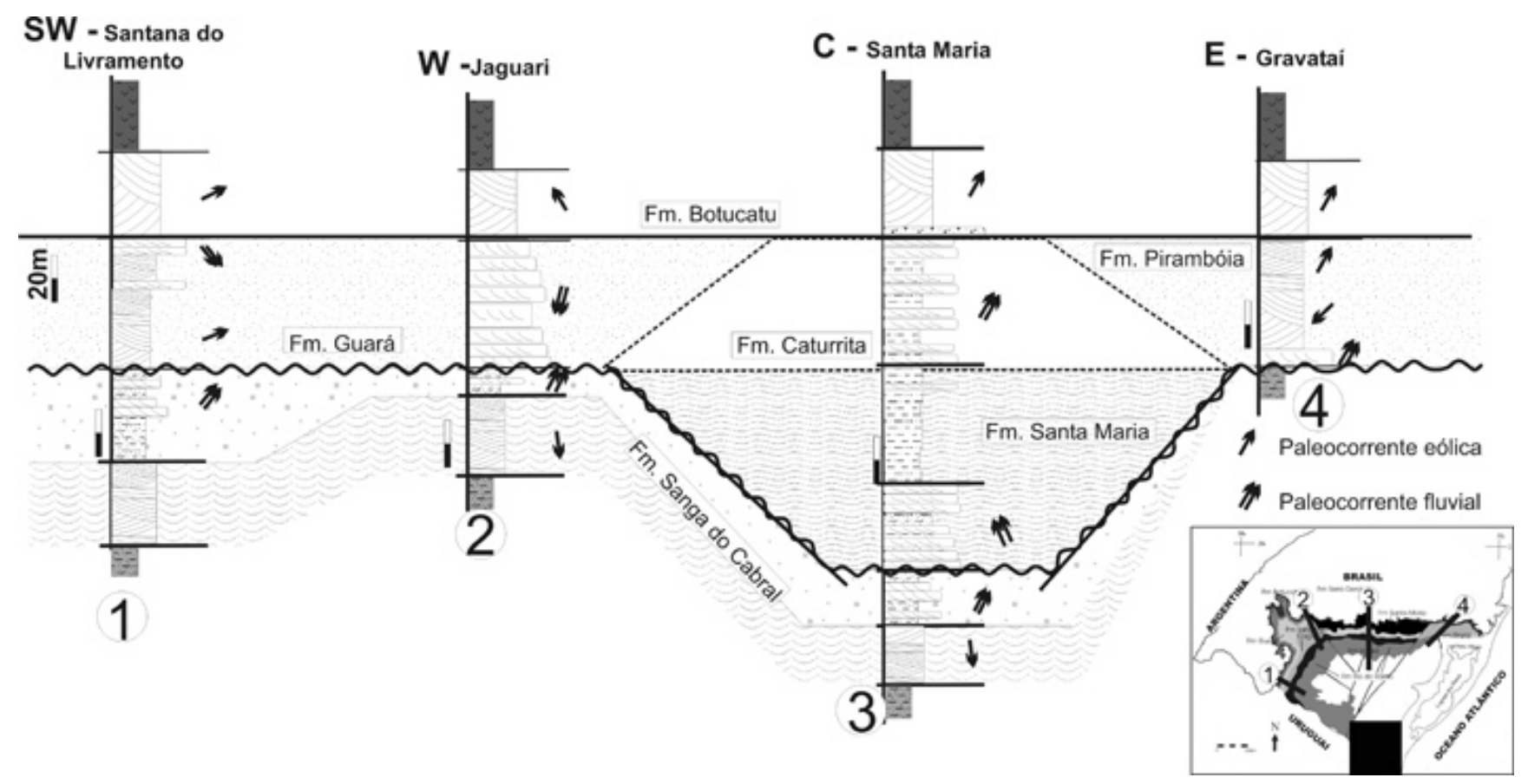

Figura 6 - Seção geológica esquemática, formada por seções colunares compostas com base em diversos autores (1 e 2 - Scherer e Lavina 2006, 3 - Montardo 1982, Faccini 2000; 4 - Soares et al. 2006), nivelada na base da Formação Botucatu. Relações espaciais entre as diferentes unidades e blocos. Apesar da situação espacial equivalente, a idade (Neo-Triássica) da Formação Caturrita não mostra crono-correlação com a Formação Guará. A zona do rifte meso e Neo-Triássica foi soerguida no Jurássico. 


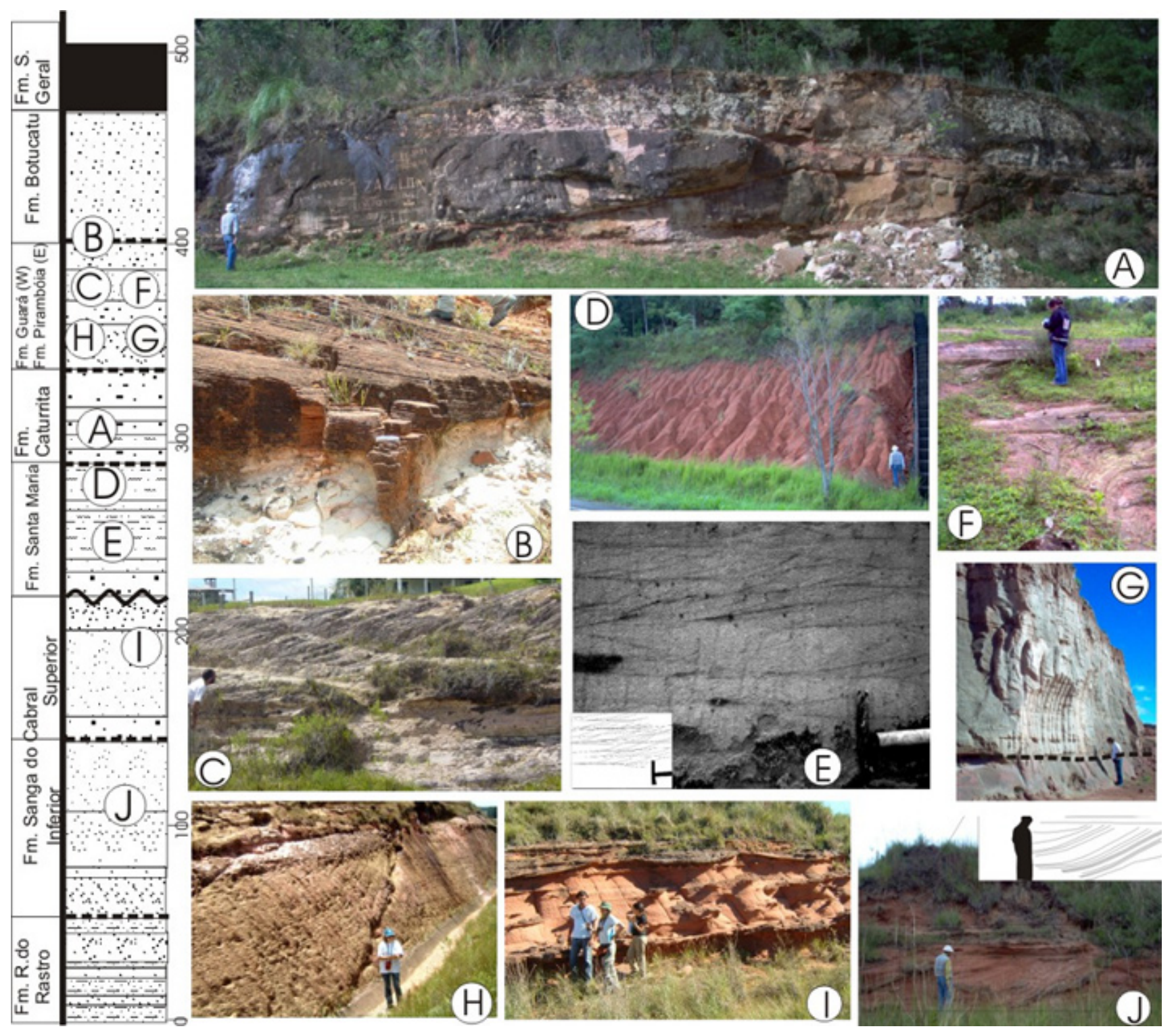

Figura 7 - Unidades Estratigráficas do SAGSUL Sul. BLOCO CENTRAL: (A) Mb.(ou Formação) Caturrita, fácies de canal anastomosado; na base, camada de pelito avermelhado com porção brechada. (D) Mb. Alemoa (Formação Santa Maria): pelito vermelho maciço, com caliche. (E) Mb. Passo das Tropas: ar. grosso, mal selecionado, com sets centimétricos de estratificação cruzada - fácies de canal entrelaçado. (I) ar. gr, níveis conglomeráticos na base das lentes, estrat. cruzada, geometria de canal largo e raso; intercalado em ar. fino com matriz argilosa - Sistema fluvial da Formação Sanga do Cabral. (J) ar. avermelhado bem selecionado com estratificação cruzada e subhorizontal do sistema eólico de duna e interduna da Formação Sanga do Cabral. BLOCO OESTE: (B) base: ar. fino esbranquiçado com matriz argilosa (Formação Guará) e no topo ar. md-gr avermelhado com estratificação cruzada de baixo ângulo (Formação Botucatu); contato entre as formações Guará e Botucatu, destaque para a estrutura "fentes en coin". (C) Sistema eólico úmido, Formação Guará: ar. fn esbranquiçado com sets de estrat. cruzada tangencial truncadas por plano-paralelas com estruturas de adesão e ar. maciço. (H) Sistema fluvial, Formação Guará: ar. md mal selecionado com estrat. cruzada tangencial. Elemento arquitetural de feição de canal; down stream acretion (DA). BLOCO LESTE $(F, G)$ ar. bem selecionado sets de até $1 \mathrm{~m}$ com estrat. cruzadas intercaladas com estrat. plano paralelas - Sistema eólico, fácies de duna e interduna úmida. (J) contato entre fácies fluvial da Formação Rio do Rasto e fácies de canal da base da Formação Pirambóia.

O SAGIN Com o objetivo de integrar as informações da faixa de afloramentos com a de poços no interior da bacia foram compostas diversas seções estratigráficas. A seção longitudinal (Fig. 8), de norte a sul na bacia, nivelada na base da Formação Botucatu revela a geometria pré-deformação das unidades, uma vez que este contato registra um marco na posição do nível freático no deserto, momento em que uma mudança climática 


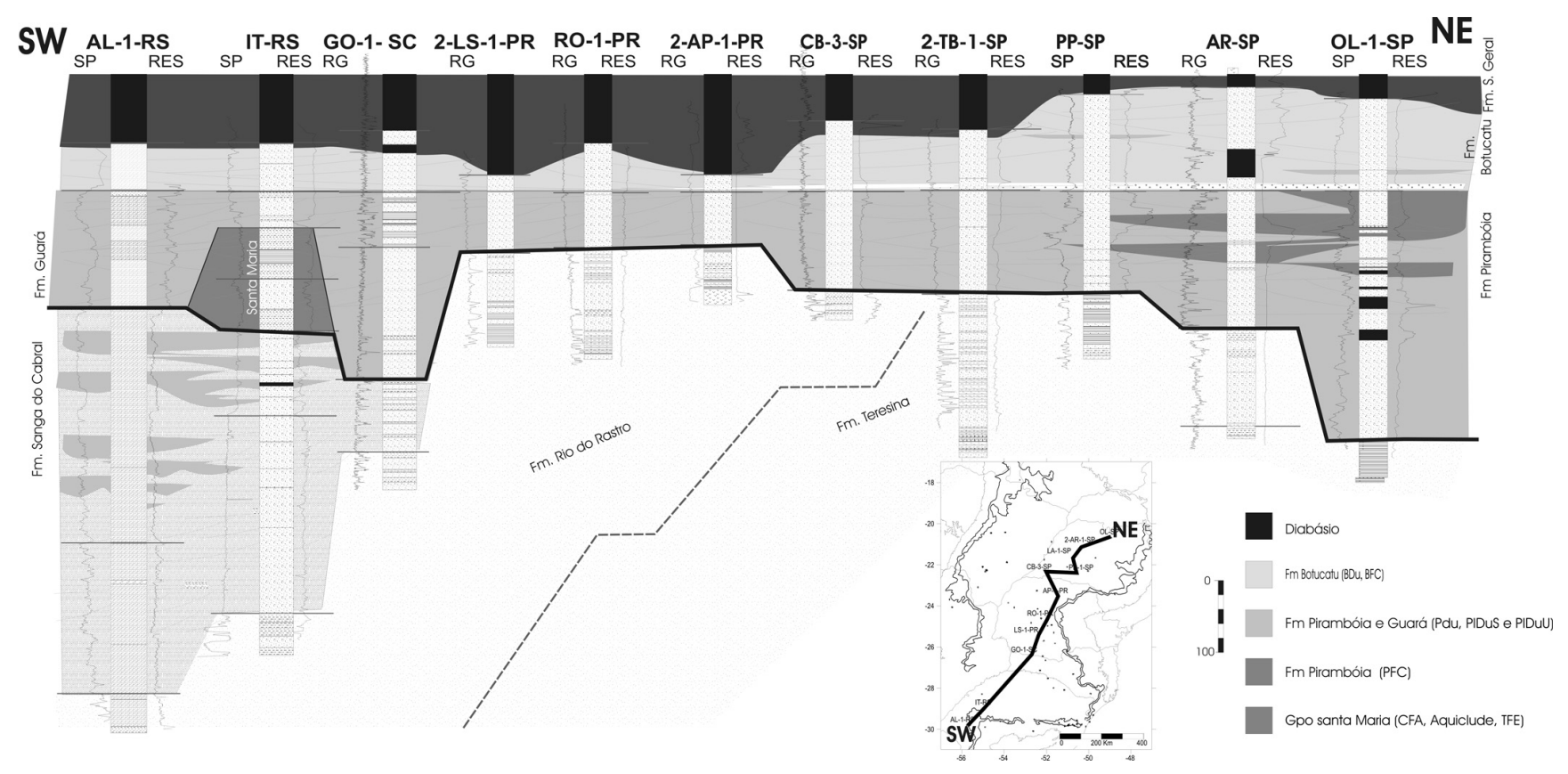

Figura 8 - Seção estratigráfica longitudinal, nivelada na base da Formação Botucatu, mostrando as relações espaciais entre as diferentes unidades componentes do SAG e unidades confinantes, substrato permiano e cobertura basáltica eo-cretácica.

para clima super-árido se instalou na bacia (Holz \& Scherer 2000).

Corpos amalgamados de arenitos fluviais aparecem intercalados entre as fácies eólicas, dentro da Formação Pirambóia em vários poços, estendendo para o sul até a unidade equivalente, Formação Guará.

A sucessão das unidades sotopostas ao SAG, cada vez mais antigas de sul para norte (ex: formações Rio do Rasto, Estrada Nova, Aquidauana, Figs. 3 e 8), é uma expressão notável da discordância permiana. A variação de espessura da Formação Pirambóia, aumentando para oeste, é indicativa de controle tectônico (Fig. 9-A). A variação de espessura da Formação Pirambóia, aumentando para oeste, é indicativa de controle tectônico (Fig. 9-A). A seção não detecta a existência das unidades Triássicas da Formação Santa Maria. Estas estariam presentes possivelmente apenas no poço IT1-RS, incluídas na parte inferior do SAG, constituindo uma extensão para noroeste do bloco central do Rio Grande do Sul.

A geometria típica da Formação Botucatu, com elevada variação geomórfica no topo revela a morfologia dunar e de grandes ergs, que antecedeu os derrames (Fig. 9-B).

Um aspecto notável das unidades sotopostas é a cor vermelha característica em todas as unidades que se justapõem ao sistema aqǘffero. Esta cor representa um processo de laterização, associado à prolongada infiltração de águas meteóricas, em clima quente de estação seca, que acompanhou a discordância pré-Mesotriássica, e que na maior parte da bacia se estendeu até o Jurássico.

A seção longitudinal do SAGIN (Fig. 8) revela ainda a existência de três diferentes compartimentos interiores: a) parte norte da bacia, sub-bacia de São Paulo e Mato Grosso do Sul, com grande espessura do Pirambóia e embasamento na seção pelítica do Permiano e Carbonífero; b) no oeste do Paraná, com menor espessura do Pirambóia, elevada compartimentação estrutural e embasamento na seção pelito-arenosa do Permiano; c) na parte meridional da bacia, com maior diferenciação estratigráfica e estrutural embasamento na seção arenoso e areno-pelítica do Permiano a Eo-Triássico.

\section{DISCUSSÃO: HIDROESTRATIGRAFIA DO}

SAG Cada componente estratigráfico do reservatório com associação de fácies delimitada e definida foi considerada uma unidade de fluxo potencial. São unidades de volume mapeável do reservatório. Suas propriedades geológicas e petrofísicas afetam a eficiência do fluxo do fluido, permitindo a previsão de sua produtividade (Hearn et al. 1984; Ebanks et al. 1993).

Considerando as diversas unidades componentes da supersequência mesozóica pré-Serra Geral, foram identificadas as principais unidades de fluxo no SAG (Tab. 2) e classificadas de acordo com sua importância, distribuição regional e continuidade lateral.

A Formação Botucatu distribui-se com poucas diferenciações faciológicas, mas com grandes variações de espessura, variando de 0 a $120 \mathrm{~m}$. Apenas uma unidade de fluxo é significativa regionalmente, a associação de fácies de duna (BDU), enquanto as demais fácies têm ocorrência restrita. As heterogeneidades internas desta unidade de fluxo são as estratificações e as superfícies de deflação entre dois complexos dunares. Possuem estruturas internas de queda e fluxo de grãos, que fazem variar o arcabouço dos grãos e sua permeabilidade. As superfícies entre os sets de estratificações e entre as duas principais unidades hidroestratigráficas 

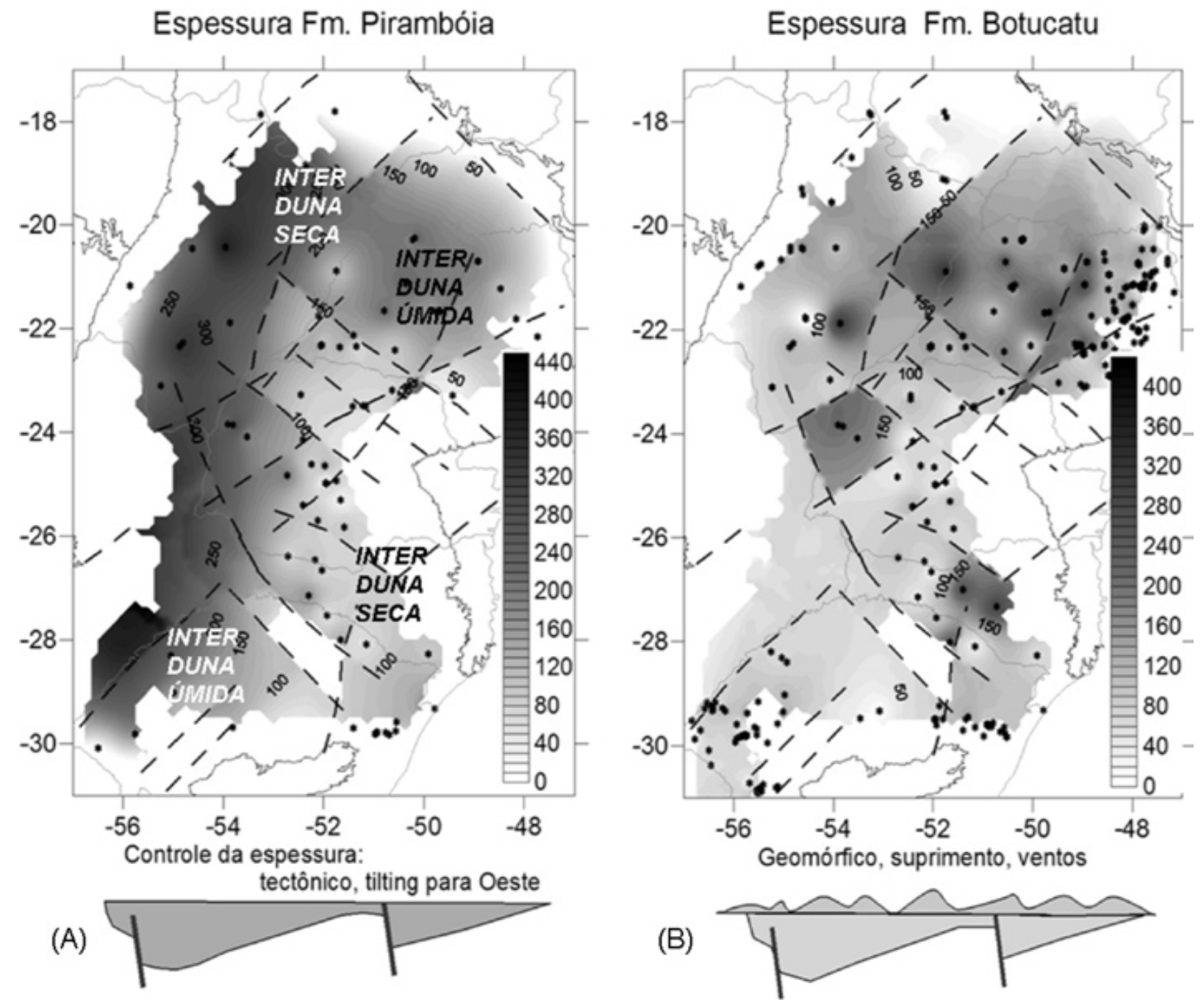

Figura 9 - Mapas (A) e (B) representam a espessura das formações Pirambóia e Botucatu respectivamente. Interpolação de dados de poço (indicados no mapa). Localização dos domínios de interdunas úmidas e secas no mapa da Formação Pirambóia. Desenho esquemático demonstrando a condicionante tectônica que controla as espessuras das unidades.

do SAG também limitam heterogeneidades cuja diferença de condutividade hidráulica alcança uma ordem de grandeza. A unidade conglomerática (BFC), formada em canais (oueds) e planícies de deflação com cascalho residual, ocorre tipicamente onde na formação sotoposta (Pirambóia, Caturrita, Guará) ocorrem também arenitos conglomeráticos fluviais.

A Formação Pirambóia possui grande variação faciológica, podendo ser dividida em três unidades de fluxo predominantes: dunas (PDU), interdunas úmidas (PIDu) e secas (PIDs) e canais fluviais (PCF). Existem ainda, em menor quantidade, as fácies pelíticas de lago e planície de inundação na interduna (FF). Cada elemento possui características granulométricas, estratificações e geometria externa diferentes.

Para inferência da condutividade hidráulica das unidades que compõe o SAG, consideraram-se preferencialmente as unidades de ocorrência extensiva, formações Botucatu e Pirambóia e equivalentes; estas uni- dades foram subdivididas com base nas composições faciológicas e elementos arquiteturais, especialmente os três componentes principais: duna, interduna e fluvial (Tab. 3).

Os sistemas de dunas eólicas produzem uma extensa cobertura de reservatório de corpos arenosos com permo-porosidade primária excelente e relativamente uniforme, como ocorre em grande parte da Formação Botucatu. Esta característica dá o aspecto de uniformidade e continuidade ao SAG.

Já na Formação Pirambóia são freqüentes os depósitos locais de interdunas úmidas, pobremente selecionados, com muita incorporação de argila por adesão na superfície deposicional úmida. As intercalações de wadis ou sabkha ocupam cerca de $50 \%$ de sua espessura. Estas fácies podem ser identificadas nos perfis, pela resistividade, radiometria e mergulho da estratificação (Fig. 10-A), especialmente no SAGNE-E. A comparação dos dados de resistividade aparente entre as forma- 
Tabela 2 - Correlação das Unidades Hidroestratigráficas componentes de SAG com Unidades de fluxo. Valores de espessura média, geometria e distribuição, e heterogeneidade.

\begin{tabular}{|c|c|c|c|c|c|c|}
\hline $\begin{array}{c}\text { Unidade } \\
\text { Hidroestratigráfica }\end{array}$ & $\begin{array}{l}\text { Unidades de } \\
\text { fluxo }\end{array}$ & $\begin{array}{l}\text { Sigla } \\
\text { usada }\end{array}$ & $\begin{array}{l}\text { Espessura } \\
(\mathrm{m})\end{array}$ & $\begin{array}{l}\text { Geometria, } \\
\text { distribuição }\end{array}$ & $\begin{array}{c}\text { Heterogeneidade } \\
\text { vertical }\end{array}$ & $\begin{array}{c}\text { Heterogeneidade } \\
\text { lateral }\end{array}$ \\
\hline \multirow{4}{*}{$\begin{array}{c}\text { BOTUCATU, } \\
\text { Misiones (sup.) } \\
\text { Taquarembó (sup.) }\end{array}$} & $\begin{array}{l}\text { Fácies dunar } \\
\text { interderrame }\end{array}$ & IDU & 50 & Lenticular, restrita & baixa & Baixa \\
\hline & $\begin{array}{c}\text { Fácies dunar pré } \\
\text { derrames }\end{array}$ & $\mathrm{BDU}$ & $0-120$ & $\begin{array}{c}\text { Tabular, contínua, } \\
\text { extensiva }\end{array}$ & baixa & Baixa \\
\hline & Conglomerado & $\mathrm{BFC}$ & $0-10$ & Irregular, local & alta & Alta \\
\hline & $\begin{array}{l}\text { Pelito-arenito } \\
\text { lacustre }\end{array}$ & Aquitarde & $0-30$ & Lenticular, local & alta & Baixa \\
\hline \multirow{4}{*}{$\begin{array}{c}\text { Pirambóia, } \\
\text { Guará } \\
\text { Taquarembó (inf.) } \\
\text { Missiones (inf.) }\end{array}$} & Fácies dunar & PDU & $10-20$ & $\begin{array}{l}\text { Lenticular } \\
\text { amalgamado, } \\
\text { recorrente, extensiva }\end{array}$ & moderada & Moderada \\
\hline & $\begin{array}{c}\text { Fácies de } \\
\text { interduna úmida }\end{array}$ & $\begin{array}{l}\text { (PIDu) } \\
\text { aquitarde }\end{array}$ & $0-20$ & $\begin{array}{c}\text { Tabular, recorrente, } \\
\text { extensiva }\end{array}$ & alta & Moderada \\
\hline & Fácies de canal & $\mathrm{PFC}$ & $0-100$ & $\begin{array}{c}\text { Lenticular, } \\
\text { amalgamada, restrita }\end{array}$ & alta & Alta \\
\hline & $\begin{array}{l}\text { Fácies de } \\
\text { interduna seca }\end{array}$ & PIDs & $0-10$ & $\begin{array}{l}\text { Lenticular } \\
\text { amalgamado, } \\
\text { recorrente, local }\end{array}$ & baixa & Baixa \\
\hline Caturrita & Fácies de canal & CFA & $0-40$ & $\begin{array}{l}\text { Descontínua, } \\
\text { lenticular, restrita }\end{array}$ & alta & Alta \\
\hline Alemoa & $\begin{array}{l}\text { Lacustre e } \\
\text { planície de } \\
\text { inundação }\end{array}$ & Aquiclude & $0-40$ & $\begin{array}{l}\text { Descontínua, } \\
\text { lenticular, restrita }\end{array}$ & moderada & Moderada \\
\hline Passo das Tropas & Fácies de canal & TFE & $0-40$ & $\begin{array}{c}\text { Descontínua, } \\
\text { lenticular, restrita }\end{array}$ & alta & Alta \\
\hline
\end{tabular}

ções Botucatu e Pirambóia revelam a diferença tanto da composição da rocha como da água, sendo notável que a resistividade aparente dos arenitos limpos da Formação Botucatu é maior que aqueles da Formação Pirambóia, exceto na parte mais profundas da bacia, mostrando que as águas são mais salinizadas na Formação Botucatu em profundidade, enquanto que nas partes mais rasas as águas mais salinizadas encontram-se na Formação Pirambóia (Fig. 10-B).

A variação de espessura da unidade Pirambóia revela um controle estrutural e uma faixa alongada de maior espessura com direção norte-nordeste, ao longo da calha da bacia, com distribuição assimétrica. No estado de São Paulo há outra zona de maior espessura, com direção noroeste. Estas maiores espessuras refletem o embaciamento, associado com falhas, certamente com influência na distribuição das diferentes fácies. A presença de arenitos de granulometria grossa, com estratificação de baixo ângulo, interpretados como depósitos fluviais, na parte mais central, nos poços situados próximo da calha, desde o norte da bacia conforme as seções apresentadas (p.ex. OL-SP, RA-MS, SE-SC, GO-SC, AL-RS, IT-RS, CB-SP), pode significar um zoneamento faciológico fluvial na Unidade Pirambóia, ainda não definido. A presença deste sistema fluvial está esboçada na figura 11, mostrando provável exten- são desta unidade de fluxo.

A unidade fluvial Pirambóia (PFC) predomina na sub-bacia de São Paulo. Possui uma distribuição restrita com largos canais escoando para sul (Fig. 11) nas zonas de maior subsidência. Da mesma forma a unidade de fluxo PIDu domina na mesma região de forma extensiva. A Unidade PIDs predomina na região noroeste e no sudeste, refletindo condições deposicionais mais secas com maior suprimento de areia (SAGNW-W) e menor subsidência (SAGSE).

Unidades de Fluxo Cada ambiente deposicional resulta numa combinação distinta de elementos arquiteturais cujas relações de maturidade textural definem a porosidade e permeabilidade da rocha (Fig. 12-A e B, Folk 1966).

Para mesma porosidade, a unidade DU tem permeabilidade dobrada em relação à unidade ID (Fig. 10-B) em virtude dos elementos arquiteturais que as compõem (Liu et al. 2002). Esta diferença se dá principalmente devido à seleção granulométrica e à intercalação de lâminas de granulometria fina na interduna.

As unidades de crevasse são isoladas nos depósitos finos da planície de inundação (FF); são delgadas e muito descontínuas, sem expressão regional, como as demais. A unidade de transbordamento FF se comporta 
Tabela 3 - Caracterização das unidades de fluxo que compões o SAG. Relacionando as unidades estratigráficas, associações de fácies e unidades de fluxo.

\begin{tabular}{|c|c|c|c|c|c|c|c|c|}
\hline \multirow{3}{*}{$\begin{array}{c}\text { Variação da } \\
\text { espessura }(\mathrm{m})\end{array}$} & \multirow{2}{*}{\multicolumn{2}{|c|}{$\begin{array}{c}\text { Fm. BOTUCATU } \\
50-100 ;(\mathrm{NW}) \\
80-120 ;(\mathrm{NE}-\mathrm{C}) \\
50-80 ;(\mathrm{SE}) \\
0-100 ;(\mathrm{S}) \\
\end{array}$}} & \multirow{2}{*}{\multicolumn{3}{|c|}{$\begin{array}{c}\text { Fms. PIRAMBÓIA e GUARÁ } \\
\text { 150-300; (NW, W) } \\
80-300 ;(\text { NE-C) } \\
80-200 ;(\text { SE e S) } \\
0-160 ;(\text { SW }) \\
\end{array}$}} & \multicolumn{3}{|c|}{ Fm. SANTA MARIA } \\
\hline & & & & & & $0-40$ & $0-60$ & $0-40$ \\
\hline & $\mathrm{BDU}$ & $\mathrm{BFC}$ & $\mathrm{PDU}$ & $\begin{array}{c}\text { PIDu } \\
\text { (aquitar- } \\
\text { de) }\end{array}$ & PFC & $\mathrm{CFC}$ & $\mathrm{TFC}$ & $\begin{array}{c}\text { ALF } \\
\text { (aquiclude) }\end{array}$ \\
\hline $\begin{array}{c}\text { Elemento } \\
\text { Arquitetural }\end{array}$ & $\begin{array}{c}\text { Duna e } \\
\text { Interduna seca }\end{array}$ & canal & Duna & $\begin{array}{l}\text { Interdu-na } \\
\text { úmida }\end{array}$ & $\begin{array}{c}\mathrm{CH}, \mathrm{CR} \\
\text { Canal, } \\
\text { crevasse }\end{array}$ & $\begin{array}{c}\mathrm{CH}, \mathrm{CR} \\
\text { Canal }\end{array}$ & $\begin{array}{c}\mathrm{CH}, \mathrm{CR} \\
\text { Canal, } \\
\text { crevasse }\end{array}$ & $\begin{array}{c}\text { FF pl. in., } \\
\text { lacust }\end{array}$ \\
\hline Granulometria & $\mathrm{AF}-\mathrm{AG}$ & $\mathrm{AMG}-\mathrm{CGL}$ & AMF-AF-AM & $\begin{array}{c}\text { Arg/ } \\
\text { SilAMF-F- } \\
\text { AM }\end{array}$ & $\mathrm{AG}, \mathrm{AM}, \mathrm{AF}$ & $\mathrm{AG}, \mathrm{AM}, \mathrm{AF}$ & AG, AM, AF & $\begin{array}{l}\text { ARG, SIL } \\
\text {-AF; }\end{array}$ \\
\hline Seleção & Alta & muito Baixa & Moderada & Baixa & Muito Baixa & Moderada & Baixa & Baixa \\
\hline Arredondamento & Bem arr & Sub Arr & Arred & Sub Arred & Anguloso & Sub arred & Anguloso & Sub Arr. \\
\hline Matriz & $5 \%$ & $22 \%$ & $10 \%$ & $25-30 \%$ & $10 \%$ & $20-30 \%$ & $20-30 \%$ & \\
\hline Mineralogia & Qz, He (Fd raro) & $\mathrm{Qz}, \mathrm{Fd}$ & $\mathrm{Qz}(\mathrm{Fd})$ & Qz, Fd, Arg & $\mathrm{Qz}, \mathrm{Fd}, \mathrm{Arg}$ & $\mathrm{Qz}, \operatorname{Arg} \mathrm{Fd}$ & $\begin{array}{l}\mathrm{Qz}, \mathrm{Fd}, \mathrm{Mv}, \\
\mathrm{rg}\end{array}$ & $\begin{array}{l}\text { Qz, Arg, } \\
\text { Cc }\end{array}$ \\
\hline Cimento & $\begin{array}{l}\text { Silica } \\
\mathrm{Fe}\end{array}$ & $\begin{array}{l}\text { Silica } \\
\text { Fe }\end{array}$ & Calcita & calcita & Calcita & & & \\
\hline Estratificação & $\begin{array}{l}\text { Cruz. Tabular } \\
\text { tang. (4-20m) } \\
\text { subh. } \\
\end{array}$ & $\begin{array}{c}\text { Cruz. } \\
\text { Acanalada } \\
(1 \mathrm{~m})\end{array}$ & $\begin{array}{c}\text { Cruz. Tangencial } \\
- \text { tabular } \\
(0,5-5 \mathrm{~m})\end{array}$ & $\begin{array}{l}\text { Cruz. de } \\
\text { baixo } \\
\text { ângulo }\end{array}$ & $\begin{array}{l}\text { Cruz. tang. } \\
(1 \mathrm{~m}) \text { e mac. } \\
\text { climb, pp }\end{array}$ & $\begin{array}{l}\text { Cruz. tang. } \\
(1 \mathrm{~m}) \text { e mac. } \\
\text { climbing,pp }\end{array}$ & $\begin{array}{l}\text { Cruz. tang. } \\
(1 \mathrm{~m}) \text { e mac. } \\
\text { climb, pp }\end{array}$ & $\begin{array}{c}\text { Pp laminar } \\
\text { e maciço }\end{array}$ \\
\hline $\begin{array}{l}\text { Paleocorrentes } \\
\text { Quadrante } \\
\text { (região) }\end{array}$ & $\begin{array}{c}\text { NE-NW(NW) } \\
\text { N-SW(NE-C) } \\
\text { N-SE (SE) } \\
\text { N-SE (S) }\end{array}$ & & $\begin{array}{c}\text { NE-NW (NW) } \\
\text { N-SW (NE-C) } \\
\text { N-SE (SE) } \\
\text { NE-SE (S) }\end{array}$ & & $\begin{array}{c}\text { SW e W (NE- } \\
\text { C) } \\
\text { SW (Guará, } \\
\text { Pir.); NE(Cat.) }\end{array}$ & $\mathrm{N}, \mathrm{NW}, \mathrm{W}$ & $\mathrm{NE}$ & \\
\hline $\begin{array}{c}\text { Sistemas } \\
\text { Deposicionais }\end{array}$ & $\begin{array}{l}\text { Eólico seco- } \\
\text { ergs }\end{array}$ & $\begin{array}{c}\text { Fluvial } \\
\text { torrencial } \\
\text { oueds } \\
\end{array}$ & $\begin{array}{l}\text { Eólico úmido- } \\
\text { ergs }\end{array}$ & $\begin{array}{c}\text { Eólico, } \\
\text { planície } \\
\text { úmida, lago }\end{array}$ & $\begin{array}{c}\text { Fluvial } \\
\text { entrelaçado } \\
\text { oueds } \\
\end{array}$ & $\begin{array}{c}\text { Fluvial } \\
\text { entrelaçado }\end{array}$ & $\begin{array}{c}\text { Fluvial } \\
\text { entrelaçado }\end{array}$ & $\begin{array}{c}\text { Lacustre e } \\
\text { fluvial }\end{array}$ \\
\hline
\end{tabular}

como aquiclude, não podendo ser caracterizada como unidade de fluxo.

Utilizando dados da literatura, principalmente Freeze e Cherry (1979), foi construído o gráfico (Fig. 13), onde duas propriedades foram relacionadas: no eixo da abscissa tem-se a granulometria variando de argila $(d \Phi=8)$ a cascalho $(d \Phi=-1)$ e no eixo das ordenadas a seleção textural, em desvio padrão, varia de muito baixa $(2 \mathrm{~s}=5 \Phi)$ a muito alta $(2 \mathrm{~s}=0 \Phi)$. O gráfico revela a proporcionalidade da condutividade hidráulica com o diâmetro médio dos grãos e, exponencialmente com a seleção, como já verificado por Krumbein \& Monk (1942) e Freeze e Cherry (1979). Com base no gráfico foram atribuídos valores médios de permeabilidade para cada unidade de fluxo (Tab. 4).

A permeabilidade estimada para unidade BDU (Formação Botucatu) é até 10 vezes superior à estimada para a PID (interduna úmida da Formação Pirambóia). Estas duas unidades estão em contato na grande parte do SAGNE-E (São Paulo e Paraná), resultando numa restrição significativa para fluxo, drenagem, recarga e produtividade do aqüífero. Enquanto internamente na unidade de fluxo BDU a água percorre $10 \mathrm{~m}$, na unidade PDU percorre $3 \mathrm{~m}$ e na unidade PIDu percorre apenas
$1 \mathrm{~m}$. Na passagem vertical entre as duas unidades hidroestratigráficas, a Formação Pirambóia pode ser considerada um aquitarde, tendo em vista o acamamento horizontal e a intercalação de sedimentos finos e texturalmente imaturos, reduzindo a condutividade hidráulica vertical a pelo menos um décimo da horizontal. O mesmo fenômeno é verificado com a Formação Guará, no sudoeste do Rio Grande do Sul. No limite destas unidades heterogêneas (Botucatu DU/Pirambóia DU e Pirambóia DU/IDu) ocorrem as surgências de água, típicas da Formação Pirambóia e marcantes na paisagem desenvolvida nesta unidade.

Já na parte central do SAGSUL as heterogeneidades verticais e laterais são muito mais abundantes e significativas. O aquiclude lacustre-aluvial (ALFF) da Formação Santa Maria, constitui a principal restrição ao fluxo; ora está abaixo da Formação Botucatu DU, ora da fácies de canal da Formação Caturrita (CFC). A fácies de canal do Membro Passo das Tropas (TFC) está delimitada acima pela fácies de planície de inundação do Membro Alemoa (ALFF) e abaixo pelos arenitos e pelitos permianos da Formação Sanga do Cabral.

Embora não relacionadas com a estratigrafia duas outras questões tem que ser levantadas: a presença 

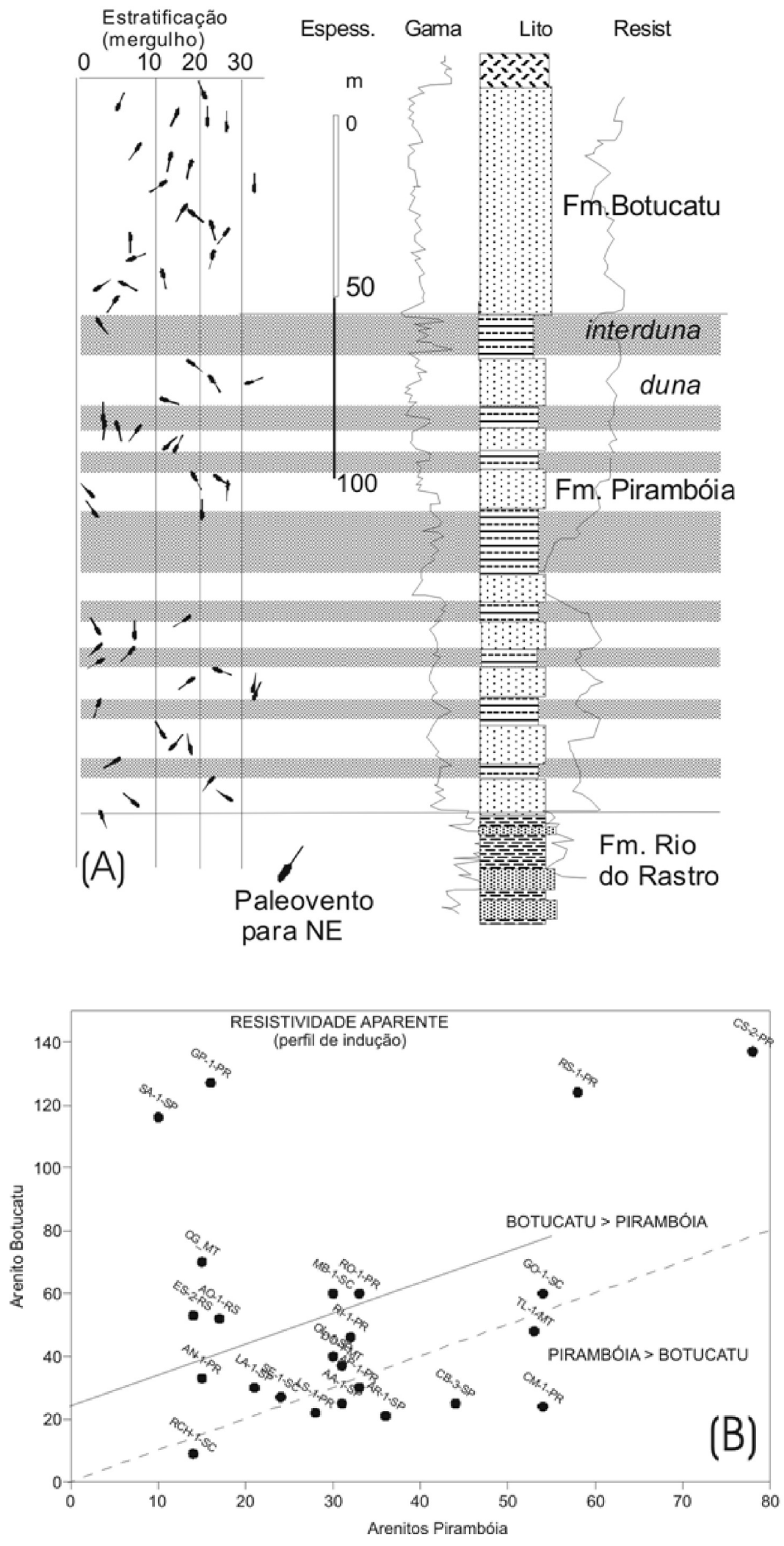

Figura 10 - Perfis típicos do SAGNE, poço TB-1-SP (São Paulo). Notar a homogeneidade da Formação Botucatu (unidade BDU) e o inter-acamamento entre interduna úmida (IDu) e duna (PDU) na Formação Pirambóia. Também é notável a mudança nas propriedades no embasamento do $S A G$, no local, a Formação Rio do Rasto. As direções de paleoventos são variáveis: $S W$ e NE na parte inferior, $\mathrm{S}$ e $\mathrm{N}$ na parte superior da Fm. Pirambóia; $S$ na Fm. Botucatu. Na figura 10-B, estão plotados os valores de resistividade aparente do perfil de indução para comparação entre as duas formações. 


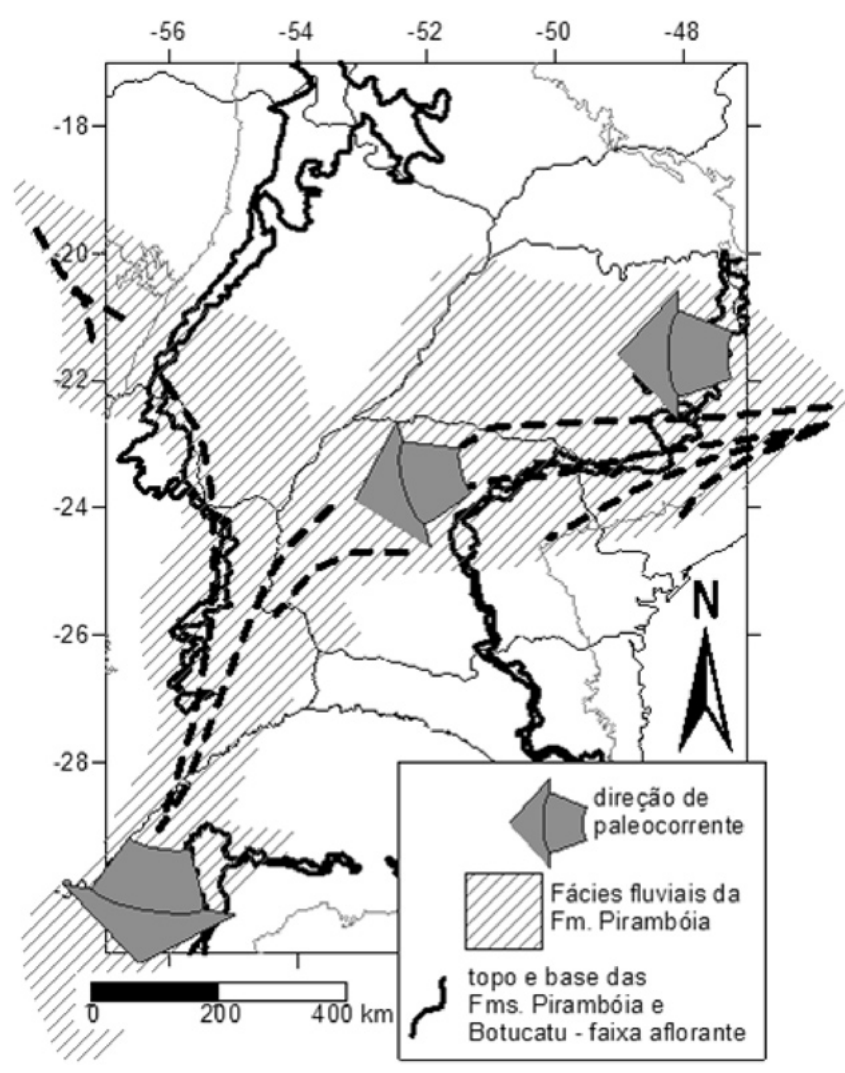

Figura 11 - Delineação esquemática da fácies fluvial interpretada a partir de dados de poços e campo. de zonas de falhas e diques que alteram as propriedades e provocam comunicação vertical, através de fraturamento intenso e restrições ou retardo no fluxo horizontal, especialmente no caso de diques delgados (Fig. 14). No caso de falhas de grande rejeito, colocando lado a lado aqüíferos e aquicludes, e de diques espessos, a restrição é severa e pode isolar compartimentos no sistema.

A segunda questão é a das alterações tanto diagenéticas como epigenéticas. Verifica-se a ocorrência de diferentes tipos de processos diagenéticos ou epigenêticos que alteram as propriedades do reservatório de forma diferente nas diferentes regiões: por exemplo, intensa calcitização epigenética no SAGNW-W parte noroeste, e silicificação no SAGNW-W parte sul (PDU, Misiones) e SAGNE-E, fácies BDU. Intensa lixiviação no SAGSE em Santa Catarina, deixando cores claras nos afloramentos e, contrariamente, intensa ferruginização e restrita silicificação no PDU e PIDs no Rio Grande do Sul. Estas questões não foram alvo de investigações sistemáticas neste trabalho. Foram abordadas em São Paulo por Caetano-Chang (1991), Meng \& Maynard (2001) e por França et al. (2003), que identificaram superposição de processos de argilização, silicificação e calcitização, em parte associados com as zonas de recarga do sistema aqüífero.

CONCLUSÕES O SAG é composto por duas unidades mesozóicas hidroestratigráficas principais: formações Pirambóia (incluindo a Formação Guará) e Botu-
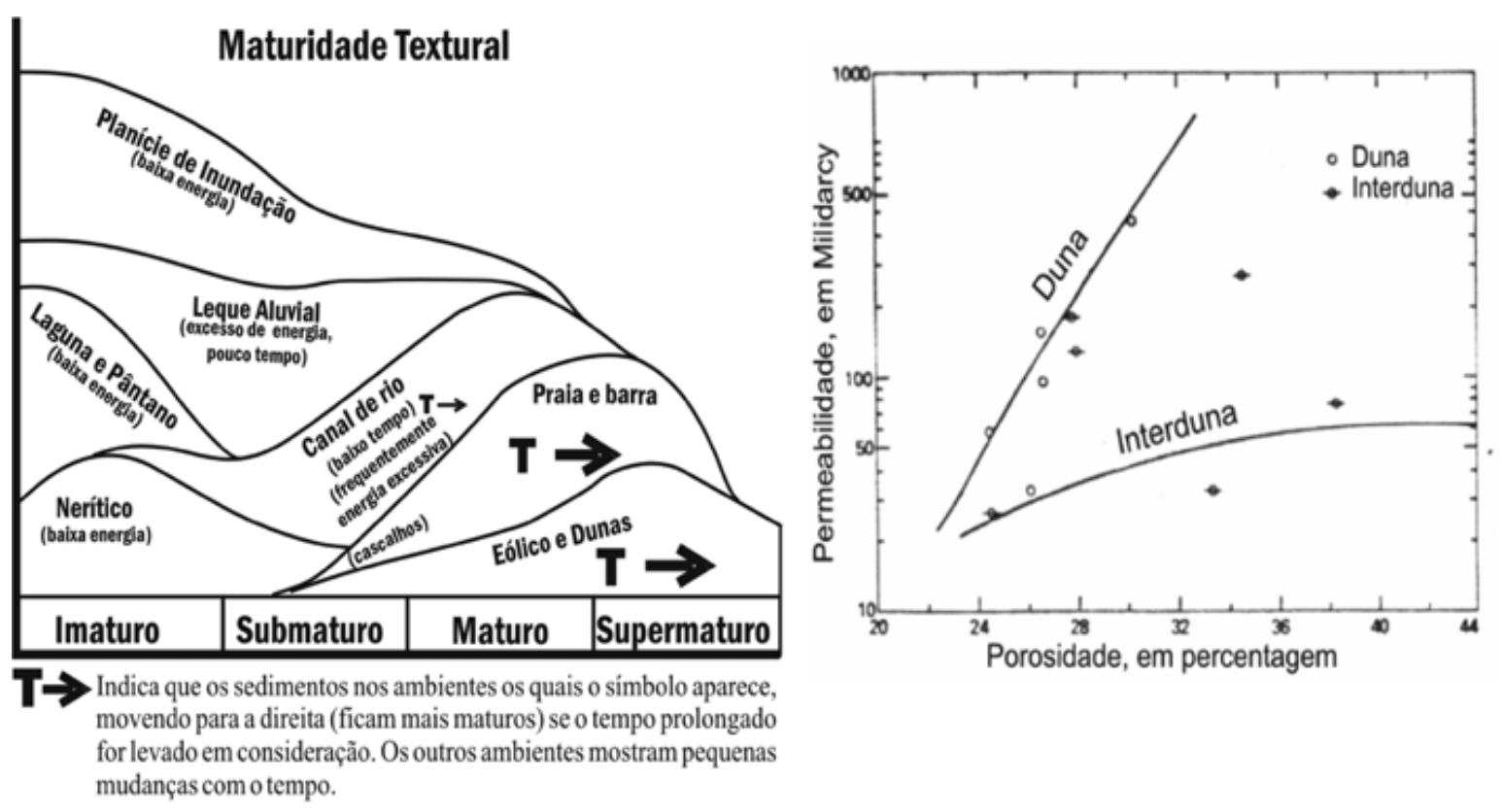

Figura 12 - (A) Gráfico esquemático ilustrando as relações entre os ambientes deposicionais clásticos e a maturidade textural dos sedimentos. Folk (1966) (B) Gráfico de porosidade versus permeabilidade, mostrando a variação destes nas unidades de fluxo duna e interduna. (Valores obtidos de $192 \mathrm{~m}$ de profundidade no testemunho de Arenito Weber de três poços no campo Brady - Sweetwater County, Wyoming, USA. Grid superimposto acima dos dados plotados.) . Freeze \&Cherry (1979). 


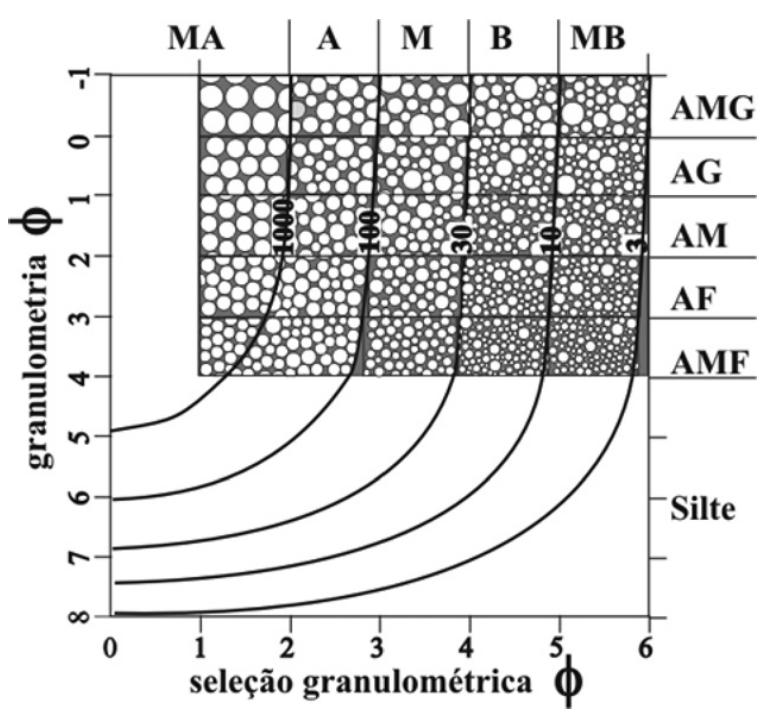

Figura 13 - Relações entre porosidade, permeabilidade, granulometria (média) e seleção granulométrica (número de classes na escala $\Phi$ ). $O$ resultado (isolinhas) é de Permeabilidade $k$, dada em milidarcy. Ilustração de grãos conforme tamanho (sem escala) e seleção granulométrica, para haver uma relação visual das proporções. ( $M A=$ muito Alta; $A=$ Alta $; M=$ média $B=$ baixa; $M B=$ muito baixa. $A M G=$ arenito muito grosso; $A G=$ arenito grosso; $A M=$ arenito médio; $A F=$ arenito fino; $A M F=$ arenito muito fino).

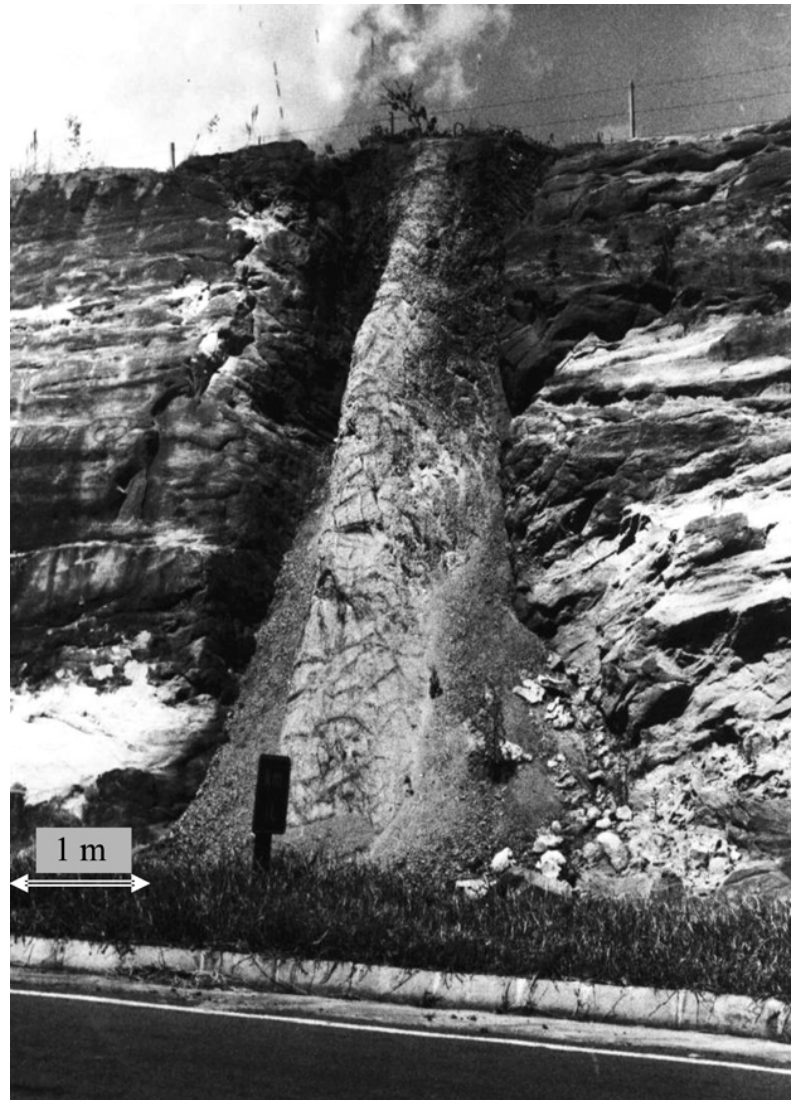

Figura 14 - Dique de diabásio intrusivo na Formação Pirambóia (Serra da Fartura, divisa Paraná - São Paulo). Observar as zonas de intenso fraturamento no arenito encaixante e no próprio dique.

Tabela 4 -Valores previstos de condutividade hidráulica, com base no gráfico da figura 11, das principais unidades de fluxo definidas do $S A G$. Sendo $D U=d u n a ; I D=i n t e r d u n a ;$ IDu=interduna úmida; $\mathrm{CH}=$ canal.

\begin{tabular}{c|c|c|c|c|c|c}
\hline $\begin{array}{c}\text { UNIDADE } \\
\text { HIDROESTRATIGRÁFICA }\end{array}$ & \multicolumn{2}{|c|}{$\begin{array}{c}\text { FORMAÇÃO } \\
\text { BOTUCATU }\end{array}$} & \multicolumn{4}{c}{ FORMAÇÃO PIRAMBÓIA } \\
\hline UNIDADES DE FLUXO & BDU-ID & CH & PDU & PIDu & PIDs & PFC \\
\hline PERMEABILIDADE, k (milidarcy) & $100-1000$ & $10-100$ & $30-100$ & $10-30$ & 30 & $1-100$ \\
\hline
\end{tabular}

catu, e secundariamente a Formação Santa Maria. A Formação Rosário do Sul ou Sanga do Cabral não pertence ao mesmo grupo, sendo esta do final do Permiano, e não se correlaciona com o sistema aqǘfero regional.

Este sistema é confinado e saturado, delimitado por uma discordância na base, em contato com diferentes unidades, desde o embasamento pré-cambriano até sobre rochas do final do Permiano ou início do Triássico. No topo é delimitado pelos derrames basálticos da Formação Serra Geral. Em São Paulo, em Goiás e Mato Grosso, raramente a Formação Serra Geral está ausente e os arenitos fluviais do Grupo Bauru assentam diretamente sobre o SAG.

Os principais elementos arquiteturais do $\mathrm{SAG}$ refletem diferentes associações de fácies e respectivamente diferentes unidades de fluxo. Foram identificadas nove unidades de fluxo de extensão regional: duas na Formação Botucatu: duna (BDU) e canal (BFC); três na formação Pirambóia: duna (PDU), interduna úmida (PIDu) e seca (PIDs), fluvial com canal e crevasse (PFC) e três na Formação Santa Maria, canal e crevasse no Mb. Passo das Tropas (TFC) e na Fm. Caturrita (CFC) e o aquiclude lamítico (Membro Alemoa), lacustre e aluvial (ALFF). Descontinuidades laterais e verticais são típicas de algumas unidades. As unidades BDU e PDU constituem os melhores reservatórios, com boa porosidade e condutividade hidráulica. Diferenciam ainda pela argilosidade maior na unidade PDU e seu 
conteúdo em águas mais salinizadas.

As unidades possuem uma grande variação de espessura ao longo da bacia. A Formação Botucatu varia de 0 a $150 \mathrm{~m}$, uma variação associada à morfologia dunar e a cobertura por derrames. A Formação Pirambóia varia de 20 a $300 \mathrm{~m}$ associada à subsidência diferencial, especialmente em faixa alongada a oeste da calha do Rio Paraná. Os alinhamentos próximos ao arqueamento de Ponta Grossa limitam menores espessuras, indicando um condicionamento estrutural sindeposicional.

O SAG é bastante complexo, heterogêneo, com diferentes espessuras e comportamentos hidráulicos. A delimitação e caracterização de compartimentos estratigráficos revelaram uma grande influência destas nas propriedades do aqüífero. A homogeneidade característica do SAG é restrita à facies dunar da formação Botucatu.

Conforme a seleção granulométrica e tamanho dos grãos de cada unidade de fluxo foram atribuídos valores de condutividade hidráulica. A unidade de fluxo DU predomina na Formação Botucatu e as unidades DU e ID predominam na Formação Pirambóia.

A condutividade hidráulica estimada para a interduna da Formação Pirambóia (PID), em grande parte da bacia ocorre sotoposta à Formação Botucatu, é dez vezes menor que a estimada para a duna da (BDU) dessa formação, o que torna a Formação Pirambóia um aquitarde em relação à formação Botucatu. Internamente na Formação Pirambóia também ocorre uma diferença de condutividade de até 3 vezes entre a unidade PDU e PID. As superfícies que delimitam estas unidades de fluxo PDU e PID apresentam barreiras ao fluxo vertical, provocando a surgência de água nestas interfaces e restrita recarga e drenagem.

Podemos concluir que o SAG é um conjunto de subsistemas, com diferentes entradas, reservatórios e saídas, com circulação controlada pelas unidades de fluxo.

Apesar de se constituir um conjunto contínuo de reservatórios, a compartimentação e diferenciação interna do SAG apontam para uma complexidade que parece ultrapassar a concepção de um sistema único.

Agradecimentos Este trabalho foi apoiado pelo CNPq através de financiamento a pesquisa (Projeto SAG - Processo 473980; 04-5). Ana Paula Soares agradece CNPq por bolsa de doutoramento (Processo 40885/2003-0). Michael Holz agradece ao CNPq por bolsa de produtividade em pesquisa (Processo 302666; 04-4).

\section{Referências}

Almeida F. 1954. Botucatu, um deserto triássico da América do Sul. Rio de Janeiro, DNPM Div. Geol. Min., Notas Prel. e Estudos 86, 21p.

Araújo L.M., França A.B., Potter P.E. 1995. Aqüifero Gigante do Mercosul no Brasil, Argentina, Uruguai e Paraguai; Mapas Hidrogeológicos das Formações Botucatu, Pirambóia, Rosário do Sul, Buena Vista, Missiones e Tacuarembo. Curitiba, UFPR PETROBRÁS, Mapas, escala 1:2.500.000

Artur P.C. \& Soares P.C. 2002. Paleoestruturas e petróleo na bacia do Paraná, Brasil. Rev. Bras. Geoc., 32(4):433448.

Assine M.L., Piranha J.M., Carneiro C.D.R. 2004. Os paleodesertos Pirambóia e Botucatu. In: Mantesso Neto V., Bartorelli A., Carnerio C.D.R., Brito-Neves B.B.de. (org.) Geologia do Continente Sul-Americano. São Paulo, Beca, p.77-92.

Bigarella J.J. \& Salamuni R. 1961. Early Mesozoic wind patterns sugested by dune bedding in the Botucatu sandstone of Brazil and Uruguay. Geological Society of America Bulletin, 72:1089-1116.

Bortoluzzi C.A., Awdziej J., Zardo S.M. 1987. Geologia da Bacia do Paraná em Santa Catarina. In: Silva L.C. \& Bortoluzzi C.A. (eds.) Texto explicativo para o mapa geológico do estado de Santa Catarina, escala 1:500.000. Florianópolis, DNPM, CRMSCTME, p.131-193.

Caetano-Chang M. R., Wu F.T., Brighetti J.M.P. Caracterização eólica de arenitos da Formação Pirambóia, proximidades de São Pedro (SP). 1991 In: SBG, Simp. Geol. Sudeste, São Paulo, Atas, 2, p.53-58.

Campy M. \& Macaire J.J. 1989. Geologie des formations superficielles. Paris, Masson, 433p.
Ebanks W.J.Jr, Scheihing M.H., Atkinson C.D. 1993. Flow units for reservoir characterization. In: Morton-Thompson D., Woods A.M. (eds.) Development geology reference manual. $A A P G$, p. 282-285.

Faccini U.F. 1989. O Permo-Triássico do Rio Grande do Sul. Dissertação de Mestrado, Pós-Graduação em Geociências, UFRGS, Porto Alegre, 121p.

Faccini U.F. 2000. Estratigrafia do Permo-Triássico do Rio Grande do Sul: estilos deposicionais versus espaço de acomodação. Tese de Doutoramento, PPGEO-UFRGS, Porto Alegre, 2 vol., 322p.

Folk R.L. 1966. A review of grain-size parameters. Sedimentology, 6:73-93.

França A.B., Araújo L.M., Potter P.E. 2003. Secondary porosity formed by deep meteoric leaching: Botucatu eolianites, southern South America. AAPG Bulletin, 87(7):1073-1082.

Freeze R.A. \& Cherry J.A. 1979. Groundwater. New Jerse, Prentice Hall, Englewood Cliffs, 604p.

Galloway W.E. \& Hobday D.K. 1996. Terrigenous clastic depositional systems: applications to fossil fuel and groundwater resources. New York, Springer, 489p.

Gamerman N. 1973. Formação Rosário do Sul. Rev. Pesq. em Geoc., 2:5-36.

Giannini P.C.F., Sawakuchi A.O., Fernandes L.A., Donatti L.M. 2004. Paleoventos e Paleocorrentes Subaquosas do Sistema Deposicional Pirambóia nos Estados de São Paulo e Paraná, Bacia do Paraná: estudo baseado em análise estatística de dados azimutais. Rev. Bras. Geoc., 34(2):282-292.

Hearn C.L., Ebanks W.J.Jr., Tye R.S., Ranganathan V. 1984. Geological factors influencing reservoir performance of 
the Hartzog Draw field, Wyoming. Journal of Petroleum Technology, 36:1335-1444.

Holz M., Soares A.P., Soares P.C. 2008. Preservation of aeolian dunes by pahoehoe lava: an example of aeolian Botucatu Formation (Jurassic) in Mato Grosso do Sul state, western margin of the Paraná Basin in South America. Journal of South American Earth Science, 25(3):398-404.

Holz M. \& Scherer C.M.S. 2000. Sedimentological and paleontological evidence of paleoclimatic change during the Southbrazilian Triassic: the register of a global trend towards a humid paleoclimate. Zentralblatt fur Geologie und Paläontologie (Teil I), Stuttgart, 11-12:1589-1609.

Krause F., Collins H.N., Nelson D.A., Machemer S.D., French P.R. 1987. Anatomia multiescalar do reservatório Pembina-Cardium, Centro-oeste de Alberta, Canadá. AAPG Bulletin, 71(10):1223-1260.

Krumbein W.C. \& G.D. Monk. 1942. Permeability as a function of the size parameters of unconsolidated sand: Am. Inst. Min. Met. Eng. Trans., 151:153-162.

Lavina E.L., Faccini U., Ribeiro, H.J.S. 1993. A Formação Pirambóia (Permo-Triássico) no Estado do Rio grande do Sul. Acta Geologica Leopoldensia, 38(1):179-197.

Liu K., Paterson L., Wong P., Qi D. 2002. A sedimentological approach to upscaling. Transport in Porous Media, 46(2,3):285-310.

Meng S.X. \& Maynard J.B. 2001. Use of statistical analysis to formulate conceptual models of geochemical behavior: water chemical data from the Botucatu aquifer in São Paulo State, Brazil. Journal of Hydrology, 250:7897.

Montardo D.K. 1982. Estudo Geológico dos Sedimentos do Gondwana Superior na Região de Candelária a Santa Cruz do Sul. Dissertação de mestrado, IG, UFRGS, Porto Alegre, 141p.

Paim P.S., Garcia A.J., Faccini U., Lavina E.L. 2003. GEOARQ, uma abordagem integrada e aplicada da geologia sedimentar. In: Paim P.S.G., Faccini U.F., Netto R.G. (org.) Geometria, arquitetura e heterogeneidades de corpos sedimentares. São Leopoldo-RS, Editora Unisinos, p. 13-23.

Rohn R. 1994. Evolução ambiental da Bacia do Paraná durante o Neopermiano no leste de Santa Catarina e do Paraná. Tese Doutoramento, Inst. de Geociências, Universidade de São Paulo, São Paulo, 2v., 188p.

Rosa Filho E.F., Salamuni R., Bittencourt A.V.L. 1987. Contribuição ao estudo das águas subterrâneas nos basaltos no Estado do Paraná. Boletim Paranaense de Geociências, 37:22-52.

Rosa Filho E.F., Híndi E.C., Rostirolla S.P., Ferreira F.J.F., Bittencourt A.V.L 2003. Sistema Aquifero Guarani Considerações Preliminares Sobre a Influência do Arco De Ponta Grossa no Fluxo das Águas Subterrâneas. Rev. Águas Subterrâneas, 17:91-112.

Scherer C.M.S. \& Lavina E.L.C. 2005. Sedimentary cycles and facies architecture of aeolian-fluvial strata of the Upper Jurassic Guará Formation, southern Brazil. Sedimentology, 52:1323-1341.

Scherer C.M.S. \& Lavina E.L. 2006. Stratigraphic evolution of a fluvial-eolian succession: the example of the Upper Jurassic - Lower Cretaceous Guará and Botucatu Formations, Paraná Basin, Southern Brazil. Gondwana Research, 9(4):475-484.

Scherer C.M.S. 1998. Análise Estratigráfica e Litológica da Formação Botucatu (Eocretáceo da Bacia do Paraná) no Rio Grande do Sul. Tese de doutoramento, Universidade Federal do Rio Grande do Sul, 230p.

Schobbenhaus C. \& Lopes R. da C. (coords). 2001. Mapas de Integração da Bacia do Prata e Áreas Adjacentes. Montevidéo: CPRM/SEGEMAR/ MOPC/DINAMIGE/ SERGEOMIN, CDRom.

Schultz C.L. 1995. Subdivisão do Triássico do Rio Grande do Sul com base em macrofósseis: problemas e perspectivas. Comunicações do Museu de Ciências e Tecnologia, UBEA/PUCRS, Serie Ciências da Terra (Porto Alegre), 1:25-32.

Soares P.C. 1974. Elementos estruturais da parte nordeste da Bacia do Paraná: Classificação e Gênese. In: SBG, Congr. Bras. Geol., 28, Porto Alegre, Anais, 1:107-121.

Soares P.C. 1981. O Jurássico e Cretáceo na Bacia do Paraná, Brasil. In: Volkheimer W. \& Musacchio E.A. (org.) Cuencas Sedimenrias del Jurássico y Cretacico de Sudamerica. Buenos Aires: Comité Sudamericano del Jurassico y Cretacico, 1:223-243.

Soares P.C. 1992. Tectônica Sinsedimentar Cíclica na Bacia do Paraná: Controles. Tese Apresentada à UFPR, Departamento de Geologia, Curitiba/PR em Concurso para Professor Titular, 148p.

Soares P.C. \& Landim P.M.B. 1973. Aspectos regionais da estratigrafia da Bacia do Paraná no seu flanco nordeste. In: SBG, Congresso Brasileiro de Geologia, 27, Aracaju, Anais, 1:243-256.

Soares A.P., Soares P.C., Bettu D.F., Holz M. 2008. Compartimentação estrutural da bacia do Paraná: a questão dos lineamentos e sua influência na distribuição do Sistema Aquifero Guarani. Geociências (São Paulo), 26:297-311.

Soares A.P., Soares P.C., Holz M. 2008. Correlações conflitantes no limite Permo-Triássico no sul da Bacia do Paraná: o contato entre duas Superseqüências e implicações na configuração espacial do Aqüífero Guarani. Revista Pesquisas em Geociências, 35(2):115-133.

Turner S., Regelous M., Kelley S., Hawkesworth C.J., Kirstein L., Mantovani M.S. 1994. Magmatism and continental breakup in the South Atlantic: high precision 40Ar/39Ar geochronology. Earth Planet. Sci. Lett., 121:333-348.

Weber K.J. \& van Geuns L.C. 1990. Framework for constructing clastic reservoir simulation models. Journal Petroleum Technology, 42:1248-1253.

Zalán P.V., Conceição J.C.J., Wolff S., Astolfi M.A.M., Vieira I.S., Appi V.T., Neto E.V.S., Cerqueira J.R., Zanotto O.A., Paumer M.L. 1986. Análise regional integrada da Bacia do Paraná. Rio de Janeiro, PETROBRAS (inédito).

Manuscrito ID 10754

Submetido em 25 de fevereiro de 2008 Aceito em 05 de dezembro de 2008 Sistema eletrônico de submissão 